\title{
An Integrated Evaluation of Enhanced Oil Recovery and Geochemical Processes for Carbonated Water Injection in Carbonate Rocks
}

\author{
Pedram Mahzari, Adrian P. Jones, Eric H. Oelkers \\ Earth Science Department, University College London
}

\begin{abstract}
During carbonated water injection and $\mathrm{CO}_{2}-\mathrm{WAG}$ scenarios for enhanced oil recovery, the transfer of $\mathrm{CO}_{2}$ from the aqueous phase into resident oil can cause local spatially $\mathrm{pH}$ changes, which can provoke mineral dissolution and precipitation reactions. The transfer of $\mathrm{CO}_{2}$ from carbonated water into the oil phase can also liberate its light components creating a gas phase in-situ. In this investigation, a novel method was developed to numerically simulate these complex processes using an integrated approach. Calculations took account of the results of coreflood experiments performed on a carbonate rock at $3100 \mathrm{psi}$ and $100{ }^{\circ} \mathrm{C}$ to optimise reaction parameters. Using the optimised parameters in a radial sector model, a series of simulations was performed to analyse change in rock porosity and enhanced oil recovery for large scale for carbonated water injections. Results demonstrate that mineral dissolution takes place mostly in vicinity of the injection wellbore. However, the simulation results demonstrate that injection of short cycle of carbonated water followed by plain water would alleviate the dissolution issue, while significant additional oil recovery is achieved.
\end{abstract}

\section{Introduction}

Injection of $\mathrm{CO}_{2}$-enriched water for enhanced oil recovery and $\mathrm{CO}_{2}$ storage has received substantial attentions amongst oil industry and CCS stakeholders [ (Blackford, 1987) (Christensen, 1961) (Oelkers, et al., 2008) (Alizadeh, et al., 2014) (Mosavat \& Torabi, 2014)]. The flow of $\mathrm{CO}_{2}$-saturated water (carbonated water) in oil reservoir can provoke the transfer of $\mathrm{CO}_{2}$ to the resident oil, which can lead to hydrocarbon swelling and the improved viscosity of the resident oil (de Nevers, 1964). It has been recently reported that, the $\mathrm{CO}_{2}$ transfer from carbonated water to oil would trigger an in-situ liberation of a new gaseous phase. Although, in the early stages, the in-situ gas formed is mainly composed of methane and light hydrocarbon components, the gas phase would be enriched with $\mathrm{CO}_{2}$ over time (Seyyedi, et al., 2017). This behaviour would provide enhanced $\mathrm{CO}_{2}$ storage capacity for carbonated water injection, where injected $\mathrm{CO}_{2}$ would become trapped in the a high pressure gas (Mahzari, et al., 2018). On the other hand, it has been repeatedly observed that the in-situ formed gas phase would remain immobile for high gas saturations, which can lead to the in-situ swelling of hydrocarbon phases 
(Mahzari, et al., 2018). Although there is much experimental evidence for this complex threephase flow process only a limited number of simulation and modelling studies have been performed [ (Al Mesmari, et al., 2016) (Al Mesmari, et al., 2016)].

The interaction between dissolved $\mathrm{CO}_{2}$ and hydrocarbons in the subsurface also alters fluid $\mathrm{pH}$ due to the formation of $\mathrm{HCO}_{3}{ }^{-}$[ (Meyssami, et al., 1992)]. The formation of this species lowers the $\mathrm{pH}$ of the aqueous phase, which makes the fluid reactive. As a large portion of current oil producing reservoirs are situated in carbonate rocks, reactions between carbonate minerals and $\mathrm{CO}_{2}$-rich water can affect greatly EOR (enhanced oil recovery) efforts [ (Svec \& Grigg, 2001) (Manrique, et al., 2007)]. Rock dissolution and wormhole formation in carbonate rocks during $\mathrm{CO}_{2}$ injection has been widely reported [ (Ott \& Oedai, 2015), (Snippe, et al., 2018), (Snippe, et al., 2017)]. Notably, the dissolution of carbonate rocks near injection wellbores can have significant effects on infectivity and EOR efforts. Extensive dissolution of carbonate rocks in the vicinity of injection wellbores has been inferred from analyses performed on single-phase interactions between carbonated water and calcite rich rock in the absence of hydrocarbons. The injection of $\mathrm{CO}_{2}$-enriched water in presence of and oil phase, however is complicated by the transfer of $\mathrm{CO}_{2}$ into the oil and the potential for the oil to liberate a distinct gas phase. Such systems require a more complex and robust integrated model to describe the chemical and physical evolution of the system.

Although numerous attempts have been published describing numerical simulations of the consequences of carbonated water injection into the subsurface, there is still a lack of understanding about the processes particularly in the presence of a hydrocarbon phase[ (Kechut, et al., 2011) (Foroozesh, et al., 2016)]. Some attempts to model such systems have relied on changing relative permeability parameters in these calculations [ (Kechut, et al., 2011) (Al Mesmari, et al., 2016)]. However, accumulating all dynamic parameters into a relative permeability term may be misleading. Relative permeability functions are dependent on wettability, interfacial tension, and viscosity ratio (Honarpour \& Mahmoud, 1988). Additional oil recovery due to carbonated water injection are based on $\mathrm{CO}_{2}$ transfer into the oil and the consequent swelling of the hydrocarbon phases. Therefore, changing the relative permeability for carbonated water injection may be inconsistent with the physical process. Notably, the interaction of oils with carbonated water would lead to creation of three-phase flow (Mahzari, et al., 2018), which brings in three-phase relative permeability functions and hysteresis effects (Mahzari \& Sohrabi, 2017). Therefore, the numerical simulation of this complex process requires considerations of this physical phenomena. In this study, the simulations are 
constrained to capture quantitative data and qualitative observations, which is called physicbased simulation.

This report describes a series of physic-based numerical simulations aimed to illuminate the evolution of enhanced oil recovery efforts in response to three-phase flow and geochemical interactions (i.e. dissolution and precipitation of calcite). The simulations are parameterized by taking account of experimental data. Notably, a history matching technique is used to obtain flow parameters for two coreflood experiments simultaneously. Co-history-matching (history matching of multiple coreflood experiments together) enables retrieval of $\mathrm{CO}_{2}$ transfer parameters representing both tertiary and secondary carbonated water injections. For geochemical interactions, the results of a coreflood experiment using single phase flow of carbonated water through a carbonate core are used to optimise reaction parameters. After having optimised these parameters simulations was performed to evaluate enhanced oil recovery and rock dissolution. The outcome of this history-matching and forward simulations provide an improved understanding of the rates and consequences of carbonated water injection in hydrocarbon bearing carbonate systems.

\section{Experimental data}

The experimental data used for history matching in the present study have been extracted from a recent paper published on light crude oil bearing Middle East carbonate reservoir rocks. Porescale visualisation and coreflood experiments were performed in the carbonate rocks on a recombined live oil under full reservoir conditions. Glass micromodel visualisations were performed to understand the dynamic pore-scale interactions taking place during carbonated water injections. On the other hand, the core-scale displacements would reflect the efficiency of carbonated water injection under full reservoir conditions, which are rather quantitative results. In our history matching procedure, it has been attempted to honour both quantitative (hard constraints) and qualitative (soft constraints) results. Details of experimental procedure and results can be found in [ (Mahzari, et al., 2018) (Mahzari, et al., 2017)].

Table 1 and Table 2 show the basic properties of the core and brine compositions used for the coreflood experiments. Core-1 was used for investigating the oil recovery by carbonated water injection in secondary and tertiary modes whereas, Core- 2 was employed for the single phase test where carbonated water injection was performed to study rock dissolution. The fluid properties can be found in Table 3. Firstly, the test for rock dissolution was performed where carbonated water was injected to displace plain water in the absence of oil. Figure 1 illustrates 
a summary of the single phase results where calcite dissolution can be identified from increased calcium ion concentration in the effluent and also, from x-ray CT image of the core. The injection was performed at different rates; which indicates a rate-dependent ionic profile. However, the CT image highlights a very localised dissolution at the inlet. The reason for rate dependent calcium profile was the precipitation of calcium after back pressure regulator (where $\mathrm{CO}_{2}$ comes out the carbonated water). At higher rates, the precipitations in lines/tubing were mobilised and produced, which resulted in higher calcium concentration at higher rate. Therefore, for history matching of ionic concentration, the average of these two rates was accounted.

For mass transfer and pore-scale interactions between carbonated water and live oil, Figure 2 illustrates two snapshots of micromodel experiments in tertiary and secondary modes. Gas phase formation during carbonated water injection could be directly observed. The gas phase would remain within the host oil and hence, no direct interface between gas and water. Also, the gas phase would tend to remain immobile for high critical gas saturation. On the other hand, the amount of gas saturation formed during secondary mode is notably higher than that of tertiary mode. The final gas saturation in glass micromodel for secondary was $14 \%$ and $10 \%$ for secondary and tertiary modes, respectively. The analyses of the coreflood and micromodel experiments indicated that the additional oil recovery depends primarily on the amount of formed gas phase. From the experimental results, it was identified that total saturation of hydrocarbon phases (oil+gas) remains constant during carbonated water injection. Also, from direct visualisations in late stages of micromodel experiments (Figure 3), it was identified that the gas phase would shrink and merge into the host oil ganglia, which would be translated to very low interfacial tension (IFT) between oil and gas. These are the qualitative observations that should be captured in the numerical simulations.

From the results of coreflood experiments (as depicted in Figure 4), The profiles of oil recovery and differential pressure $(\mathrm{dP})$ can be used to tune flow parameters and EOS parameters. These two coreflood experiments are selected because of similarities in injection rate and carbonation level. From experimental data, it was identified that carbonated water could bring about insignificant wettability alteration, due to similar breakthrough time in water and carbonated water injection cases. Also, the tails of $\mathrm{dP}$ profiles for water and carbonated water injection tests are similar, which can be interpreted as similar relative permeability for water in these two tests. Herein, the coreflood results were history matched honouring the qualitative observations from micromodel tests. 
Table 1: Basic properties of the core used for coreflood experiments

\begin{tabular}{|c|c|c|c|c|c|}
\hline $\begin{array}{c}\text { Sample } \\
\#\end{array}$ & $\begin{array}{c}\text { Porosity } \\
(\%)\end{array}$ & $\begin{array}{c}\text { Permeability } \\
(\mathrm{mD})\end{array}$ & $\begin{array}{c}\text { Length } \\
(\mathrm{cm})\end{array}$ & $\begin{array}{c}\text { Diameter } \\
(\mathrm{cm})\end{array}$ & $\begin{array}{c}\text { Swi } \\
(\mathrm{frac} .)\end{array}$ \\
\hline Core-1 & 25.83 & 96.21 & 25.84 & 3.75 & 0.17 \\
\hline Core-2 & 23.68 & 409 & 14.5 & 3.75 & 1 \\
\hline
\end{tabular}

Table 2: Ionic concentration of brines used for formation water and injection brine

\begin{tabular}{|l|l|l|}
\hline Ions & $\begin{array}{l}\text { Formation water } \\
(\mathrm{ppm})\end{array}$ & $\begin{array}{l}\text { Injection water } \\
(\mathrm{ppm})\end{array}$ \\
\hline $\mathrm{Na}^{+}$ & 59491 & 18300 \\
\hline $\mathrm{Ca}^{++}$ & 19040 & 650 \\
\hline $\mathrm{Mg}^{++}$ & 2439 & 2439 \\
\hline $\mathrm{SO}_{4}^{--}$ & 350 & 4290 \\
\hline $\mathrm{Cl}^{-}$ & 132060 & 32200 \\
\hline $\mathrm{HCO}_{3}{ }^{-}$ & 354 & 120 \\
\hline $\mathrm{TDS}$ & 213749 & 59046 \\
\hline
\end{tabular}

Table 3: Properties of the fluids used in micromodel and coreflood experiments

\begin{tabular}{|l|c|c|c|}
\hline Properties & Live Water & Live Oil & Carbonated water \\
\hline Viscosity (cP) & 0.350 & 0.83 & 0.38 \\
\hline Formation volume factor & 1.01 & 1.30 & 1.03 \\
\hline Solution gas ratio (ccGas/ccBrine) & 3.28 & 71.23 & 22.79 \\
\hline
\end{tabular}

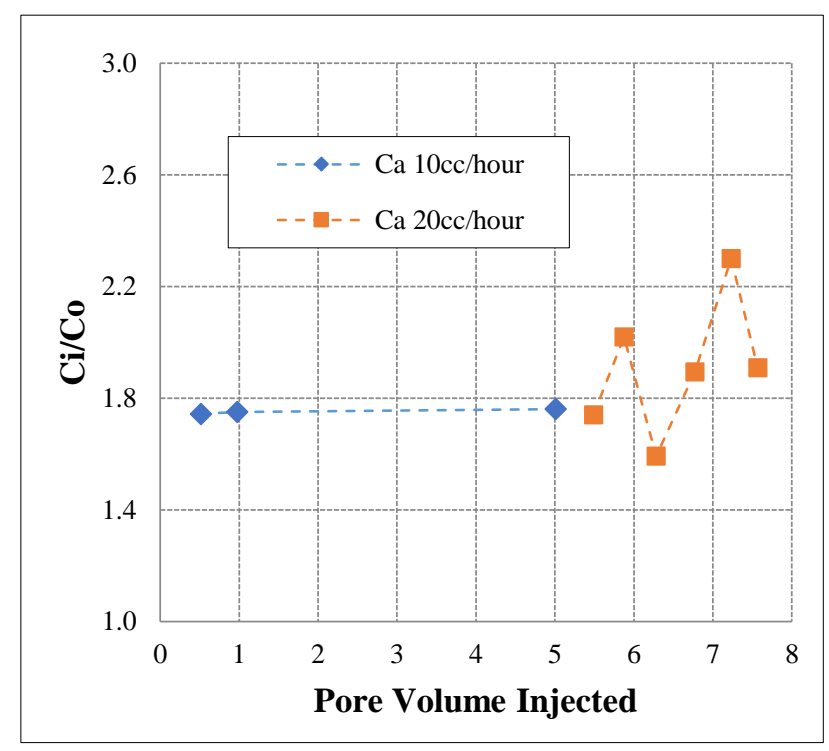

(a)

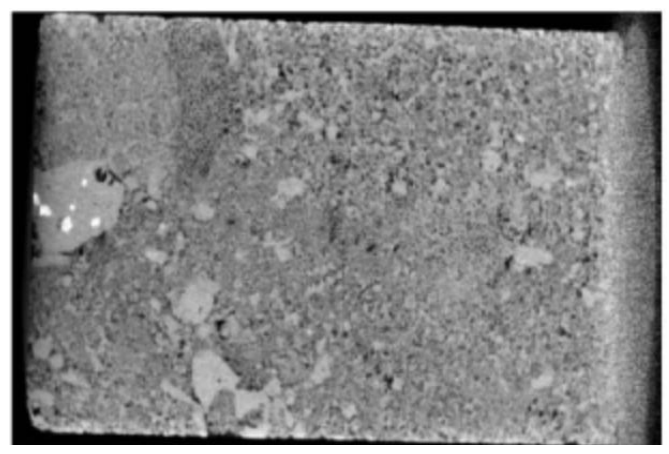

(b)

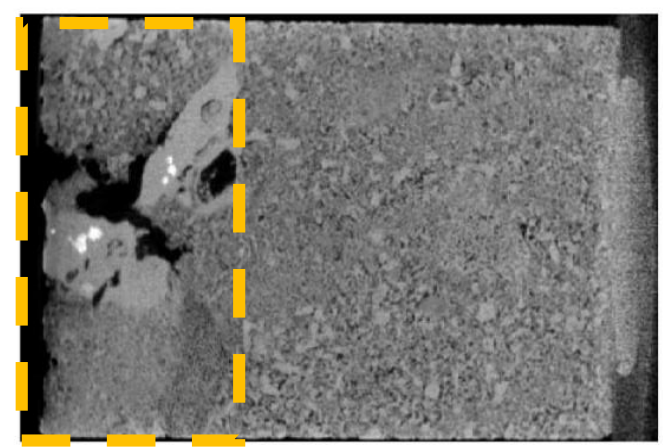

(c)

Figure 1: Results of rock dissolution during single phase carbonated water injection. (a) Concentration of calcium ion in the aqueous effluent collected during different injection rates of carbonated water injection. (b) $\mathrm{x}$-ray CT image of the core before the single phase experiment. (b) x-ray CT image of the core close to inlet after carbonated water injection: localised dissolution took place on the left of the core (core inlet) as highlighted by a yellow box. 


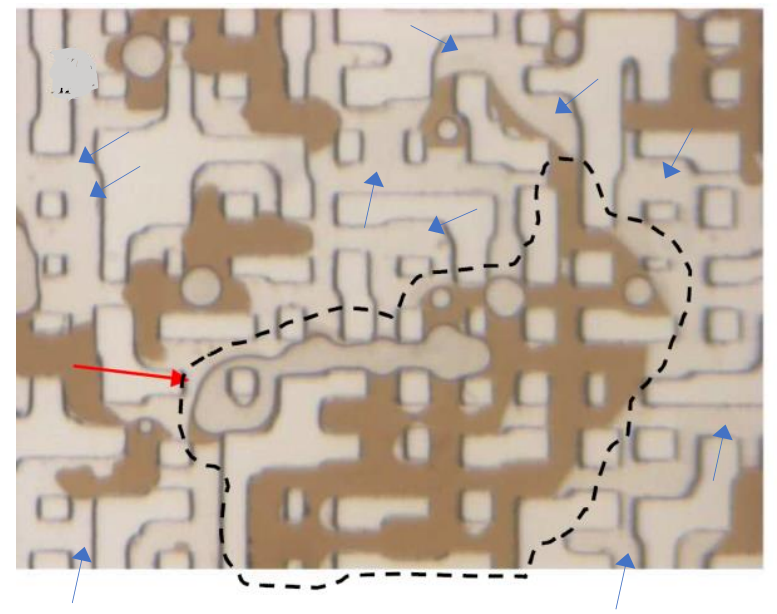

(a)

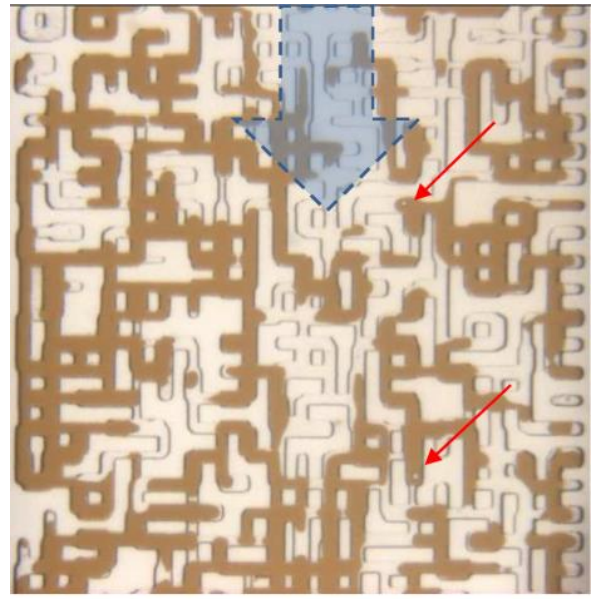

(b)

Figure 2: Micromodel visualisations of carbonated water injection in tertiary (a) and secondary (b) modes. The gas phase tends to remain within the oil phase. In secondary mode (b), the gas bubbles formed in the front of carbonated water, as shown by blue arrow. The red arrows highlight the gas phase formed within the resident oil. In the magnified images, brown phase represents live oil in glass micromodel and transparent pores were filled with aqueous phase (as highlighted by small blue arrows). Also, the gas phase formed within the oil has a transparent form, which is indicated by red arrows. The rest of images represent the rock grains.

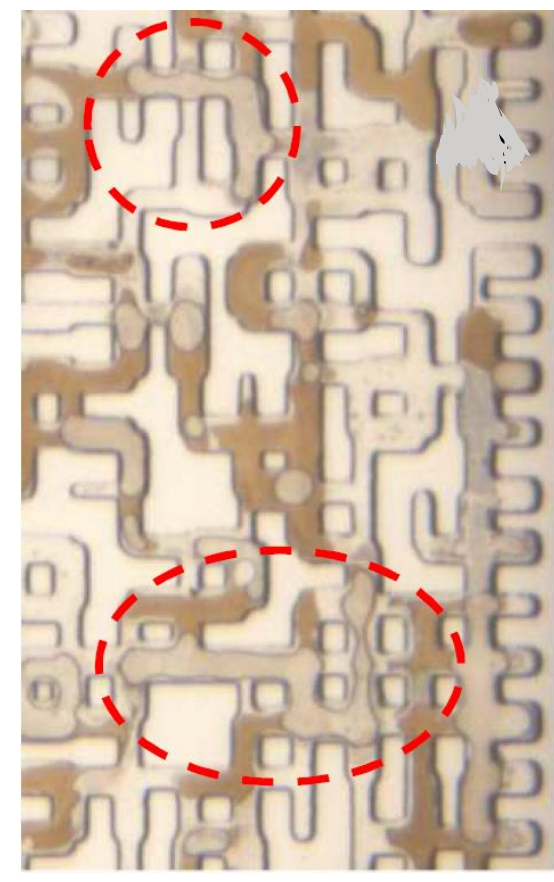

(a)

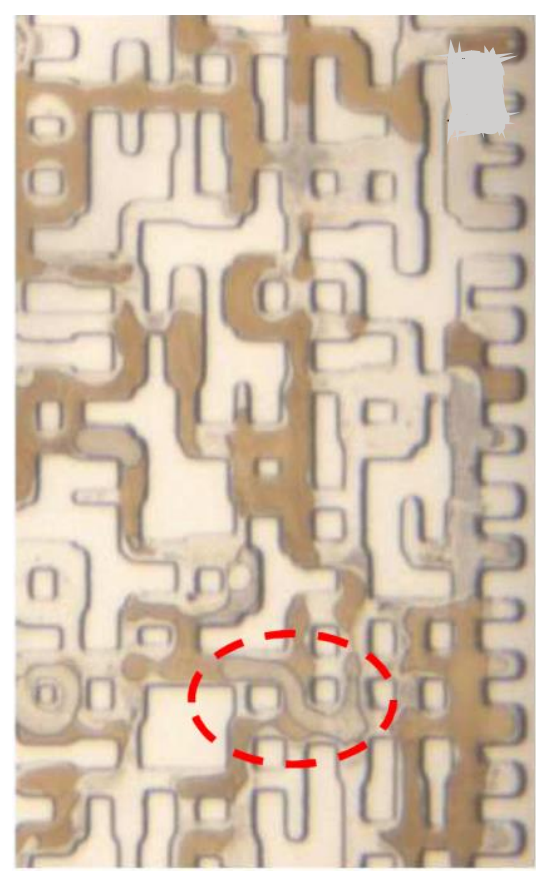

(b)

Figure 3: Two snapshots of micromodel experiment taken chronologically to demonstrate enrichment of the gas phase and eventually, it became miscible with the host oil. Red circles highlight the gas phase shrinking with time. 


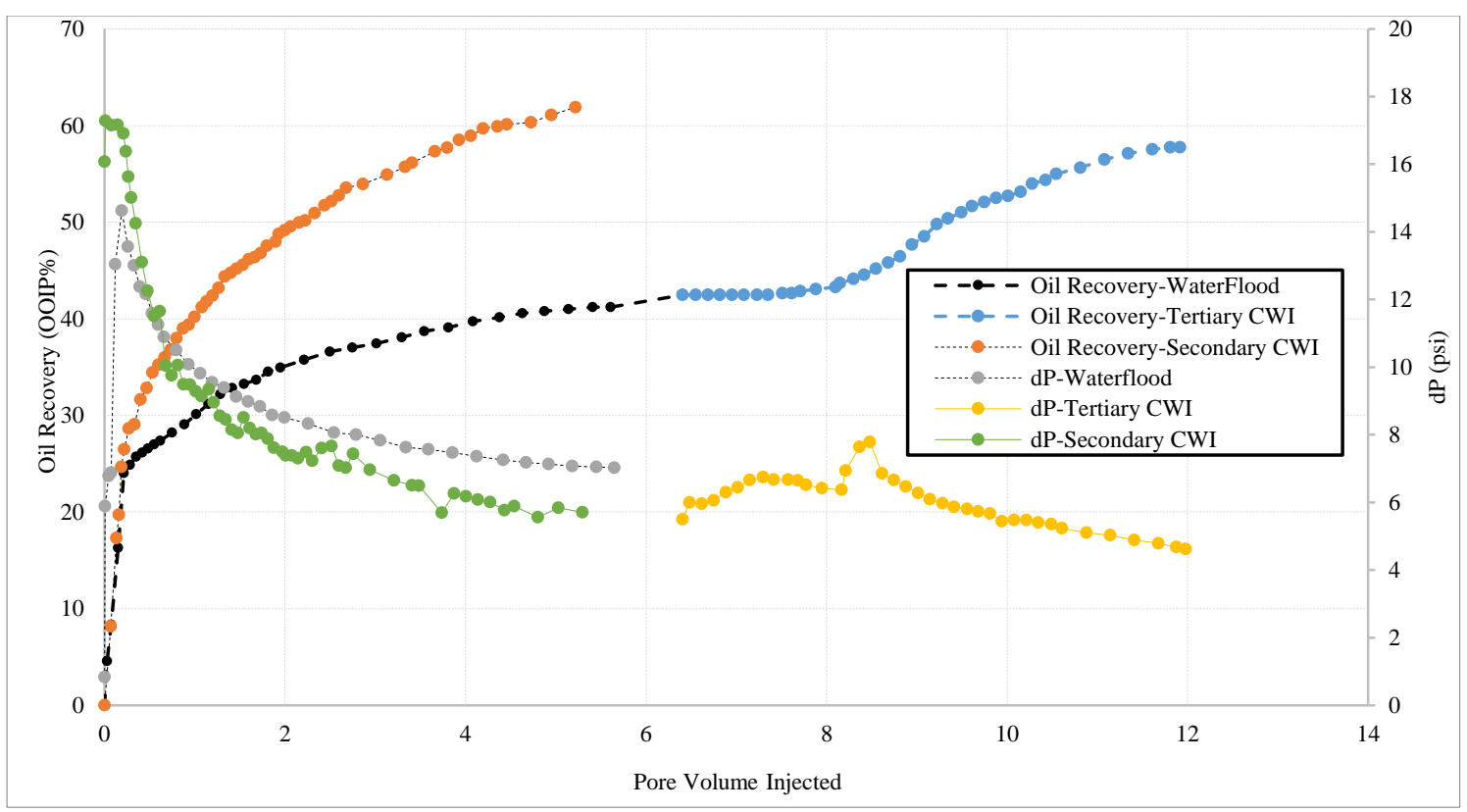

Figure 4: Results of coreflood experiments performed in secondary and tertiary modes. Additional oil recovery in secondary mode is significantly higher than that of tertiary mode, which can be attributed to initial oil and water saturations in place before carbonated water injection.

\section{Modelling approach}

Having performed a number of coreflood experiments at different modes (i.e. secondary and tertiary), all experiments can be history matched together to obtain "one" set of flow and mass transfer parameters. Tertiary and secondary modes would represent different modes of mass transfer and brine mixing. History matching of secondary carbonate water injection would highlight the presence of high oil and low water saturations initially in the core. On the other hand, in tertiary mode, high water saturation would exist due to preceding plain water injection, which would impact the $\mathrm{CO}_{2}$ transfer significantly. To be able to capture these two processes, the two coreflood experiments are history matched together. This new approach of history matching multiple coreflood together is called co-history-matching (Mahzari, et al., 2018). Simulations and history matching of multiple coreflood experiments have been proposed previously for three-phase flow to estimate hysteresis parameters [ (Mahzari \& Sohrabi, 2017) and (Douchenne, et al., 2015))]. However, the use of multiple coreflood history matching for estimation of mass transfer parameters, which are more representative of dynamic pore-scale mass transfers, are discussed in this paper for the first time. The detailed methodologies for setting up a commercial simulator for multiple coreflood history matching is presented in (Mahzari, et al., 2018).

It should be noted that, the approach proposed here is different from the conventional methodologies where, multiple corefloods with different physics are performed and simulated 
separately to obtain relative permeabilities. In conventional approach, one separate (single) coreflood is performed for water flooding (which is used for estimation of relative permeability of water-oil flow) and then, another single coreflood for EOR methods such as chemical or carbonated water injection (which is used for estimation of relative permeability of the EOR methods). This method may suffer from non-uniqueness of the history matching solutions due to separate usage of data. However, in co-history-matching, all the corefloods (multiple corefloods for the EOR method such as carbonated water or chemical) including tertiary and secondary modes will be involved in history matching "simultaneously". This latter technique would alleviate the non-uniqueness issue and also, the outcome would be consistent for different modes. One of the advantages of obtaining parameters consistent for tertiary and secondary modes is that, it can be used in reservoir simulation more readily where the EOR method (in large scales) can target the remaining oil in different forms replicating pre- and post-waterflood scenarios.

For multiple coreflood history matching, a sector model with three layers of grid blocks was considered; top layer represents the coreflood performed in tertiary mode (two sequences of water and carbonated water injection), middle layer is null blocks, and bottom layer is for the secondary mode of carbonated water injection. For this methodology, any commercial simulator can be utilised. Experimental information obtained from each coreflood can be input for producer and injector of each layer separately. With this arrangement, it would be doable to run the simulation (all three layers) with a single set of saturation functions and equation of state parameters while production and injection information are analyzed (matched) separately. This type of history matching can only be used for the experiments performed on identical systems (with same core and fluid systems). An optimizer is linked to the simulator (which runs the sector model) to tune parameters for matching the experimental data of all corefloods (coreflood=layer) together. The global objective function is defined to account for error of all corefloods together:

$$
\begin{aligned}
& \text { Global Objective function } \left.=w f_{i} \sum \text { (objective function of each coreflood }\right)_{i} \\
& \text { objective function of each coreflood }_{i}=w_{i} \sum\left(d P_{\text {exp }}-d P_{\text {sim }}\right)_{i}^{2}+w_{i}^{\prime} \sum\left(\text { Oil Vol }_{\text {exp }}-O \text { Oil Vol }_{\text {sim }}\right)_{i}^{2}
\end{aligned}
$$

Where objective function of each coreflood is used by the optimizer to be minimized for estimation of tuning parameters. In equation $2, d P$ stands for differential pressure across the core and Oil Vol represent volume of oil produced during the coreflood experiments. $w_{i}$ and $w_{i}^{\prime}$ coefficients are the weight factors given to $d P$ and $O i l$ Vol error terms. exp and sim subscripts represent experimental and simulation results, respectively. 
For setting up the simulation in this study, one-dimensional numerical simulation was constructed for each layer with 100 grid blocks using a compositional oil simulator (CMG package). For incorporating capillary end-effects, two grid blocks at the outlet were assigned with zero capillary pressure. For relative permeability and capillary pressure functions, LET formulations were incorporated to have flexible correlations (Lomeland, et al., 2005). Utilising CMG-CMOST with its CMG Designed Exploration and Controlled Evolution (CMG's proprietary algorithm) for minimization of objective functions (this is an improved genetic algorithm), which is based on estimation of posterior probability function of a parameter, which is expressed by the following equations:

$p(x)=\frac{P_{o}(x) L(x)}{\sum P_{o}(x) L(x)}$

$L(x)=e^{-Q(x)}$

Where $p(x)$ is the posterior probability function, $P o(x)$ is the prior probability function, and $L(x)$ is the likelihood function using $Q(x)$ as the objective function. The objective function is the accumulative error between experimental data and simulation results for multiple core experiments. The basis of this optimization method is the Bayesian type of minimization. In the history matching process, the minimization algorithm was continued until a cumulative error of less than $0.01 \%$ is achieved.

The mass transfer and partitioning of $\mathrm{CO}_{2}$ between aqueous and hydrocarbon phases are controlled by binary interaction coefficients and Henry constants. Henry constant would control $\mathrm{CO}_{2}$ solubility in brine as expressed in equation 5 and 6.

$f=C_{\mathrm{CO} 2} \times H$

$\operatorname{Ln}(H)=\operatorname{Ln}\left(h_{i}\right)+V_{\text {inf }} \frac{P-P_{\text {ref }}}{R T}$

Where, $f$ and $C_{\mathrm{CO} 2}$ are fugacity and concentration of a component (like $\mathrm{CO}_{2}$ ) in aqueous solution and $H$ is Henry's law constant. To calculate $H$ at elevated pressure and temperature (equation 6), Henry's coefficient $\left(h_{i}\right)$ and partial molar volume of solute at infinite dilution $\left(V_{\text {inf }}\right)$ are required. Peng Robinson equation of state (EOS) was used in this work to estimate the phase equilibria between oil and gas phases (equation 7) (Peng \& Robinson, 1976). In the cubic EOS, the second term is referred as attractive forces between molecules (Coutinho, et al., 2000). Since the attractive forces can be significantly affected by the interactions between 
various components in the solution, the concept of binary interaction coefficient is used to adjust the attractive forces in complex systems as expressed in equation 8 .

$P=\frac{R T}{V-b}-\frac{a}{V(V+b)+b(V-b)}(7)$

$a=\sum_{i} \sum_{j} x_{i} x_{j} \sqrt{a_{i} a_{j}}\left(1-k_{i j}\right)$

Where $b$ and $a$ in (7) are related to molecule sizes and attraction forces, respectively. $x$ is composition and $a$ is coefficient of $i$ and $j$ components. $k$ is called binary interaction coefficients, which is used to adjust the mixing rules for attractive forces. Binary interaction coefficients are known to be dependent on temperature and pressure and it has been reported that, binary interaction coefficients are needed to be more adjusted at elevated temperature (above $343.15^{\circ} \mathrm{K}$ ) and also for unlike components such as $\mathrm{CO} 2$ and hydrocarbon components (Coutinho, et al., 1994) (Ikeda \& Schaefer, 2011) (Fateen, et al., 2013). For $\mathrm{CO}_{2}$ solubility in the oil and consequent interactions with individual components binary interaction coefficients are considered as tuning parameters to capture experimental observations.

Therefore, to capture different mass transfer processes in tertiary and secondary modes, the tuning parameters for coreflood experiments are binary interaction coefficients between $\mathrm{CO}_{2}$ and live oil components and oil/gas relative permeability curves. The results of oil recovery and $\mathrm{dP}$ profiles were considered as the primary objective functions. Also, other observations from micromodel experiments such as gas phase saturation and declining IFT between oil and gas phases were input as soft constraints for the history matching. Furthermore, another soft constraint was the higher gas saturation in the secondary mode compared to tertiary (as visualised in micromodel experiments).

\section{Co-history-matching of EOR by carbonated water}

For the system under study in this work, previously, two-phase (oi/water) flow $\mathrm{kr}$ and $\mathrm{Pc}$ functions were estimated using co-history-matching concept for low and high rate experiments (Mahzari, et al., 2018). The outcome of co-history-matching on different rates has demonstrated that the relative strength of capillary and viscous forces can be captured by cohistory-matching of similar coreflood experiments. Therefore, here in this current work, the two-phase (oil/water) kr and Pc functions estimated from the previous work were input (as fixed parameters) in the simulations. The relative permeability and capillary pressure curves for oil and water two-phase flow can reflect an oil wet state for the core. This may have 
significant implications on rock dissolution in the core where the rock is coated with the oil. The fluid model used for the live oil can be found in Table 4, which is tuned to match basic properties of the live oil such as bubble point (test pressure and temperature), oil formation volume factor, solution gas ratio, and oil viscosity.

Table 4: EOS parameters used for the fluid model tuned on the basic fluid properties.

\begin{tabular}{|c|c|c|c|c|}
\hline Component & Pc (atm) & Tc $\left({ }^{\circ} \mathrm{K}\right)$ & Acentric factor & Molecular Weight \\
\hline CO2 & 72.8 & 304.2 & 0.225 & 44.01 \\
\hline CH4 & 45.4 & 190.6 & 0.008 & 16.04 \\
\hline C2HtoC3H & 45.36 & 335.76 & 0.121 & 36.30 \\
\hline IC4toC7 & 34.20 & 481.01 & 0.421 & 76.03 \\
\hline C8 toC9 & 28.04 & 584.29 & 0.371 & 113.74 \\
\hline C10-C15 & 25.01 & 664.10 & 0.639 & 170.34 \\
\hline C16-C20 & 19.99 & 730.98 & 0.774 & 248.54 \\
\hline C21-C25 & 19 & 778.52 & 0.8 & 318.67 \\
\hline C26-C31 & 18 & 800.00 & 0.8 & 394.75 \\
\hline C32-C33 & 17 & 800 & 0.8 & 453.96 \\
\hline C34+ & 15.99 & 799.99 & 0.8 & 636.62 \\
\hline
\end{tabular}

For carbonated water injection experiments, the co-history-matching model was arranged in a way to incorporate tertiary and secondary coreflood experiments simultaneously, as illustrated in Figure 5. The full results of the coreflood experiments were input into the model including the secondary plain water flood of tertiary carbonated water injection. In other words, the cohistory-matching exercise would honour two-phase oil/water, three-phase carbonated water flow, $\mathrm{CO}_{2}$ mass transfer from water to oil, and impact of initial oil/water saturations. Also, observations from direct pore-scale experiments (micromodel tests) are constrained to be honoured qualitatively. However, a number of simplifications have been accounted; (i) kinetics of $\mathrm{CO}_{2}$ transfer was ignored (thermodynamic equilibrium in each grid cell was assumed), (ii) geochemistry of calcite dissolution was ignored for enhanced oil recovery coreflood experiments (due to lack of experimental data for produced brine composition), (iii) capillary pressure between oil and gas was assumed to be zero, and (iv) the core was assumed to have one dimensional flow ignoring lateral and transverse heterogeneities. Heterogeneity can have a strong impact on dissolution. Depending on wettability, usually, carbonated water would flow through more permeable flow path of heterogeneity, which would lead to more dissolution in the more permeable flow path. Therefore, heterogeneity in 2-D and 3-D systems would have a significant impact. However, in our analysis, we simplified the system to 1-D flow and lumped the heterogeneity into relative permeability and capillary pressure curves. It should be noted that heterogeneity of the core could be manifested in relative permeability and capillary pressure curves as well. As the two phase oil-water relative permeability and capillary pressure 
curves were taken from (Mahzari, et al., 2018), it can be inferred that the curves would have the characteristics of heterogeneous rocks.

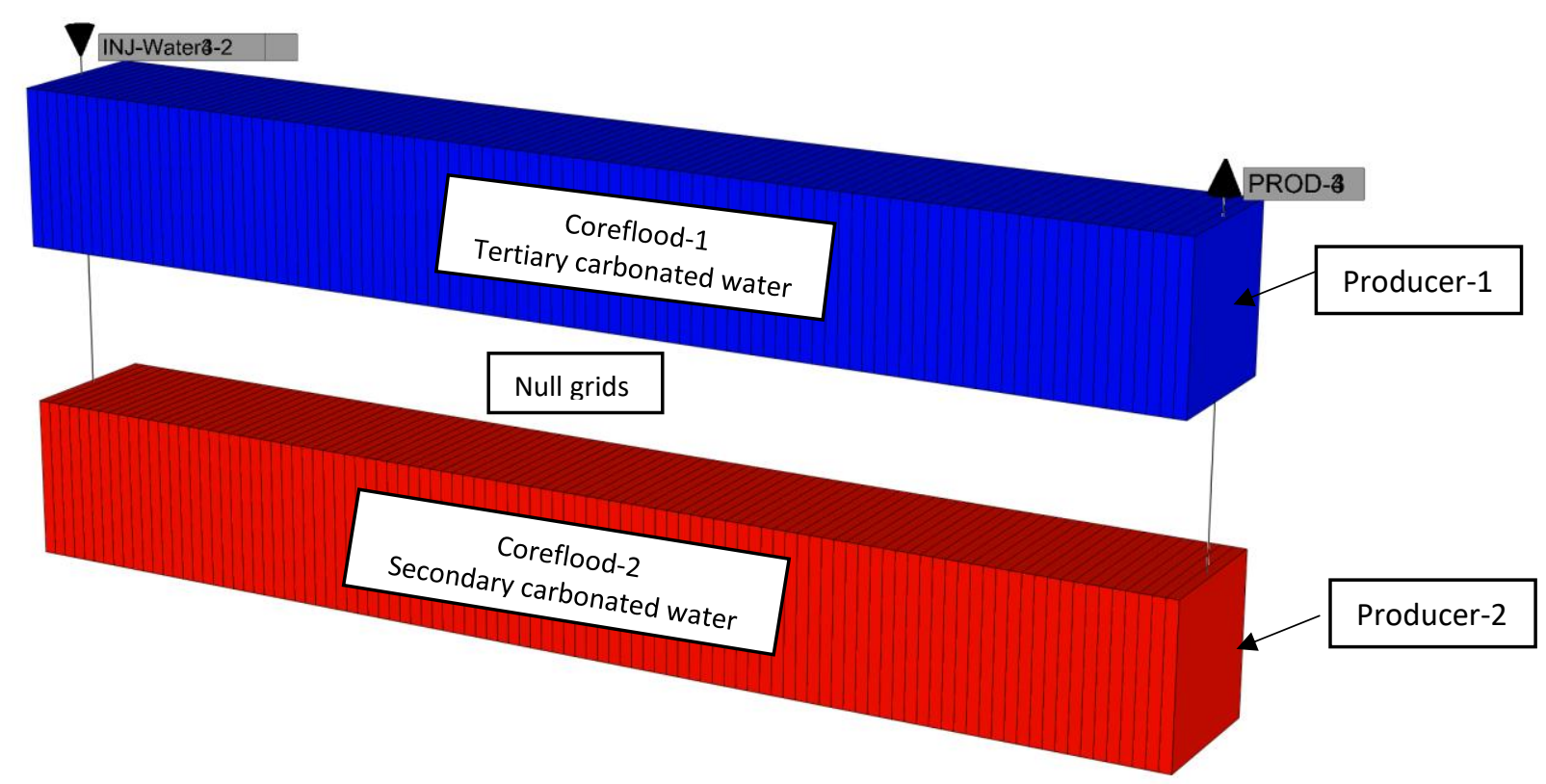

Figure 5: Sector model with three layers to represent two coreflood experiments together for co-history-matching. The upper (tertiary carbonated water injection) and bottom (secondary) layers are active cells to simulate corefloods whereas, the middle layer is assigned as null blocks. Capillary end-effects were included by two grid blocks at the end of cores with zero Pc.

One-way mass transfer of $\mathrm{CO}_{2}$ from aqueous phase to resident oil would liberate the gaseous third-phase and hence, three-phase relative permeability function is required. Three-phase flow parameters can be related to phase saturations/distributions, pore structure, wettability, spreading behaviour, and other factors (Honarpour \& Mahmoud, 1988), which is still not well understood. In this work, the impact of three-phase relative permeability is not investigated. However, it is attempted to identify a suitable model for three-phase relative permeability amongst previously proposed models. As micromodel visualisations have demonstrated (Figure 2-a), the liberated gas phase remains and grows within the host oil ganglion, which implies no direct contact between aqueous and gas phases. Moreover, the improvement in oil flow is directly related to amount of gas saturation formed during carbonated water injection. These direct observations would approximate the assumptions behind Baker model (Baker, 1988), where gas and water flow independently in a segregated mode. In Baker model, relative permeability of oil can be directly controlled by gas saturation as expressed in equation (9);

$\left(k r_{o}\right)_{3 p h a s e}=\frac{S_{g} \times k r_{g o}+\left(S_{w}-S_{w i r r}\right) \times k r_{o w}}{\left(S_{g}+S_{w}-S_{w i r r}\right)}$ 
Where $S$ stands for saturations of gas $(g)$ and water $(w) . S_{\text {wirr }}$ is the irreducible water saturation. $k r_{g o}$ and $k r_{o w}$ are relative permeability of oil from two phase gas/oil and oil/water tables. As can be inferred, $k r_{o g}$ (gas/oil relative permeability) would come into the calculation as gas phase forms and grows.

To perform co-history-matching, different weight factors for each set of experimental data (i.e. $\mathrm{dP}$ or oil recovery) was assigned, which would compensate relative importance of the data. Weight factors from 1 to 0.1 were assigned to $\mathrm{dP}$ and oil recovery profiles, respectively. Also, the tertiary carbonated water injection was given higher weight factor in history matching process. Tertiary mode of carbonated water would represent the $\mathrm{CO}_{2}$ transfer from aqueous phase to residual oil saturation ( $S_{\text {or }}$ after waterflood). Also, the tertiary displacements would consist of mixing between preceding water and invading carbonated water. Thus, more weight factors to tertiary experiments would ensure capturing these physics during co-historymatching.

Figure 6 and Figure 7 depict the results of co-history-matching performed for secondary and tertiary carbonated water injection experiments. Given the complex processes exist during carbonated water injection, an acceptable degree of similarities could be attained for both experiments with one set of saturation functions and $\mathrm{CO}_{2}$ mass transfer parameters. The quality of the match is more acceptable for the tertiary experiment (Figure 6) due to higher weight factors assigned. For the tertiary experiment, the results of co-history-matching could capture the part of the experiment before the start of additional oil recovery, which can be attributed to mixing of brines and insufficient gas-phase formation, while it could reproduce the increasing trend of $\mathrm{dP}$ profile. For secondary mode of carbonated water injection, although the final oil recovery could be simulated, the profile of oil recovery after breakthrough of carbonated water was under-estimated by simulation results. Simulation results for $\mathrm{dP}$ of secondary carbonated water injection has exhibited a slight difference with the experimental data. These minor differences can be attributed to assumptions made in the simulation runs.

To compare the results of co-history-matching with single coreflood history matching, a single coreflood history matching was performed where the tertiary carbonated water injection was history matched and then, the parameters obtained from single coreflood history matching were used for predicting secondary carbonated water injection. The quality of history matching of the tertiary carbonated water was identical to Figure 6. Also, relative permeability functions are input similar in two cases. However, when the phase behaviour parameters of single history 
matching were used, the prediction of secondary carbonated water injection was become poor compared to co-history-matching, which indicates the advantage of co-history-matching over single coreflood history matching. It should be pointed out that, for the single coreflood history matching the full cycle of waterflood followed by carbonated water was history matched. However, due to non-uniqueness issue, the outcome of single coreflood history matching may not necessarily lead to reliable set of tuned parameters.

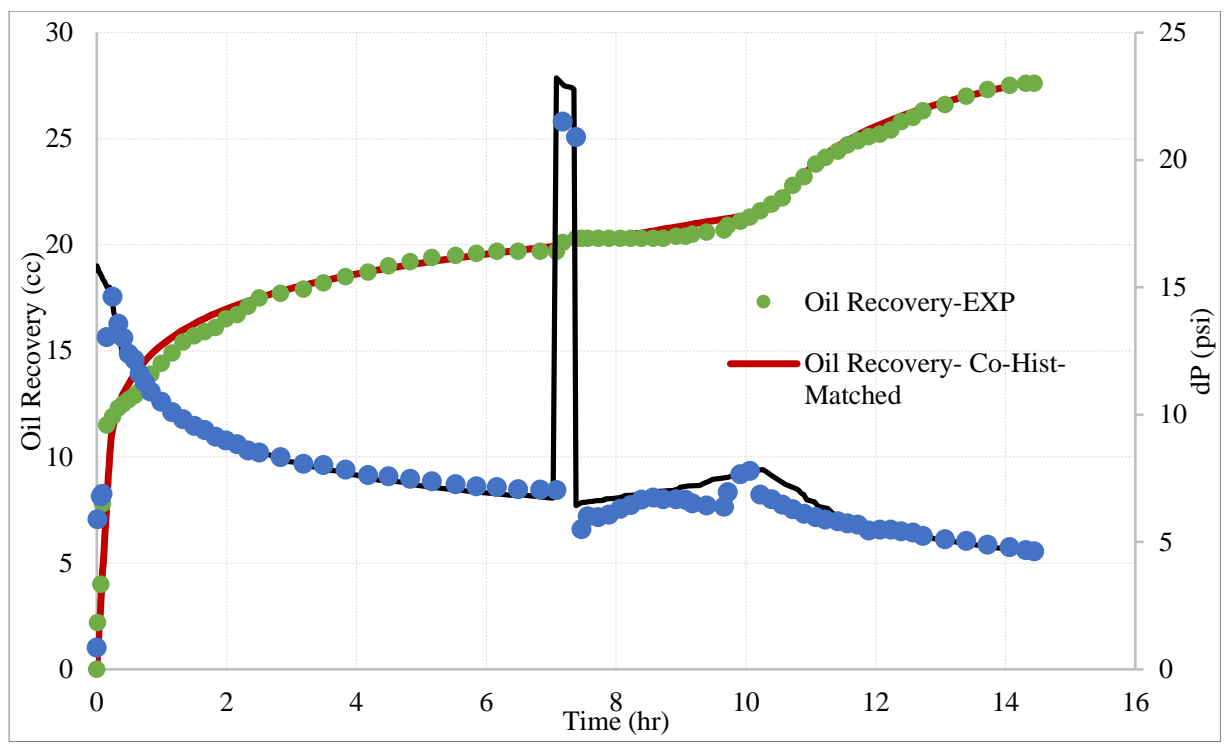

Figure 6: Results of co-history-matching (solid lines) and experimental data (dots) of dP and oil recovery for secondary plain water injection followed by tertiary carbonated water injection. Acceptable similarities can be achieved between model and experiment.

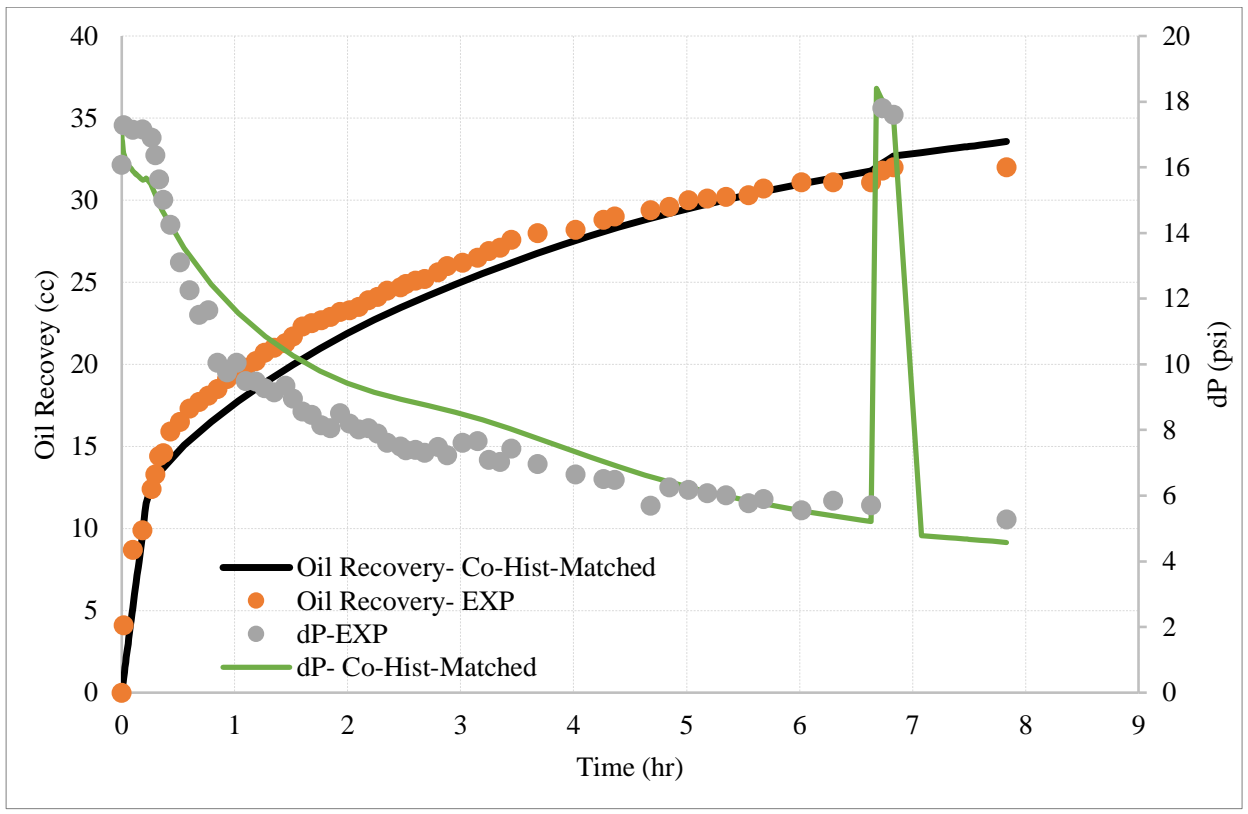

Figure 7: Results of co-history-matching (solid lines) and experimental data (dots) of $\mathrm{dP}$ and oil recovery for secondary carbonated water injection. Acceptable similarities can be achieved between model and experiment. 


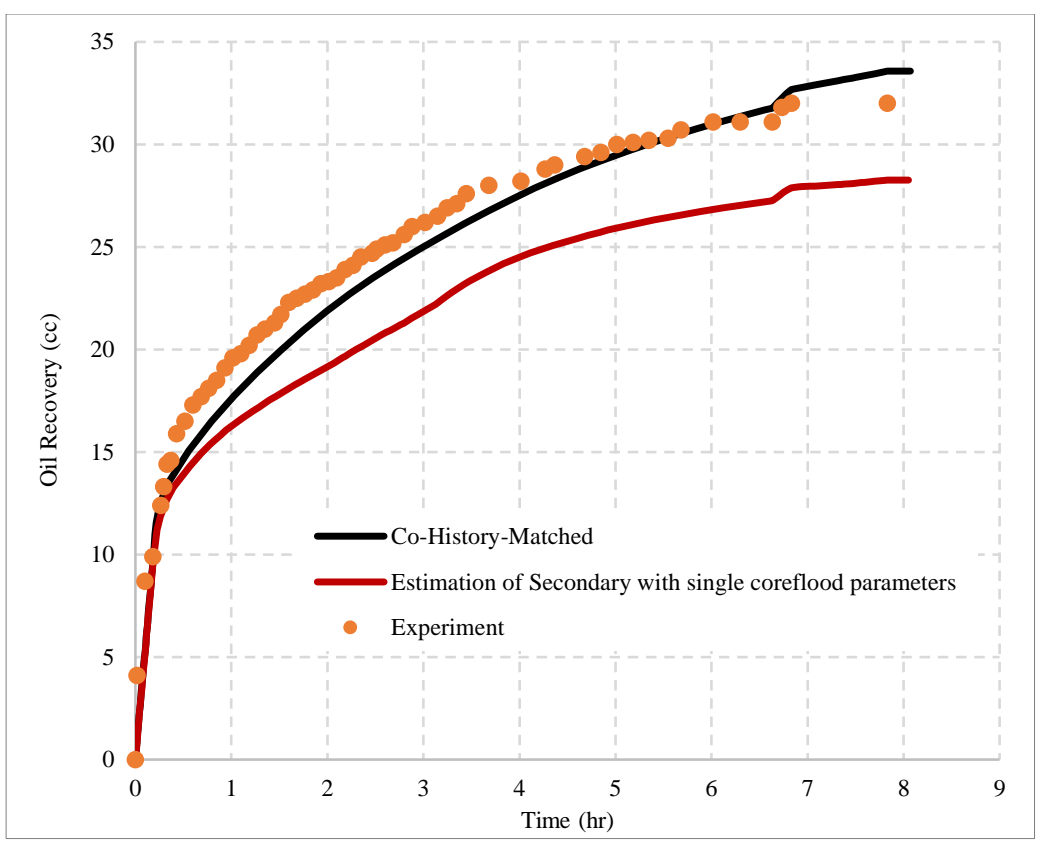

Figure 8: Simulation results of the secondary carbonated water injection experiments using parameters tuned from two approaches: (i) co-history-matching and (ii) parameters tuned from history matching of single coreflood (i.e. tertiary carbonated water injection). A better match between co-history-matched and experimental data was attained indicating the advantage of co-history-matching over conventional history matching approach.

Figure 9 shows the tuned relative permeability functions obtained from co-history-matching of secondary and tertiary coreflood experiments. In history-matching of the coreflood experiments, not all saturation ranges of fluids can be reliably matched due to lack of information about in-situ saturation measurements. Hence, the pertinent saturation ranges of relative permeability curves are limited to the areas highlighted by the red boxes in Figure 9 . The critical gas saturation $\left(S_{\text {gcrit }}\right)$ beyond which gas starts to flow was 0.15 which is very close to what was directly observed in micromodel experiment. The gas relative permeability at saturations above $S_{\text {gcrit }}$ is very low indicating the flow characteristics of the formed gas, which remains within oil ganglia. This result is in agreement with observation of micromodel experiments, where small bubbles of formed gas could flow very slowly once they could merge and form relatively large gas bubbles. Moreover, the oil relative permeability in gas/oil twophase curves has shown an approximately constant values for gas saturation of 0 to 0.2 . This behaviour of relative permeability can be linked to the experimental data where the oil rate in the secondary mode is almost steady and constant after water breakthrough. Therefore, the outcome of saturation functions can be interpreted by physical findings observed in the experiments. 
Table 5 shows the binary interaction coefficients between $\mathrm{CO}_{2}$ and hydrocarbon components as obtained from co-history-matching and also, the parameters obtained from single coreflood history matching, which highlights the non-uniqueness issue with limited data of the single coreflood history matching. Binary interaction coefficients are known to be the adjusting parameters that can improve the results of EOS estimations. Due to polarity of $\mathrm{CO}_{2}$, it has been expected to encounter high values of binary interaction coefficients for non-polar/polar components. As can be seen in this table, the binary interaction coefficients can have different values depending on the size and properties of the hydrocarbon components, since the binary interaction coefficients can be affected by geometric mean for the cross energy between unlike molecules [ (Coutinho, et al., 1994) (Coutinho, et al., 2000)]. As shown in equation 8, as binary interaction coefficients diverge from zero, more adjustments are to be imposed on the EOS to improve the estimations.

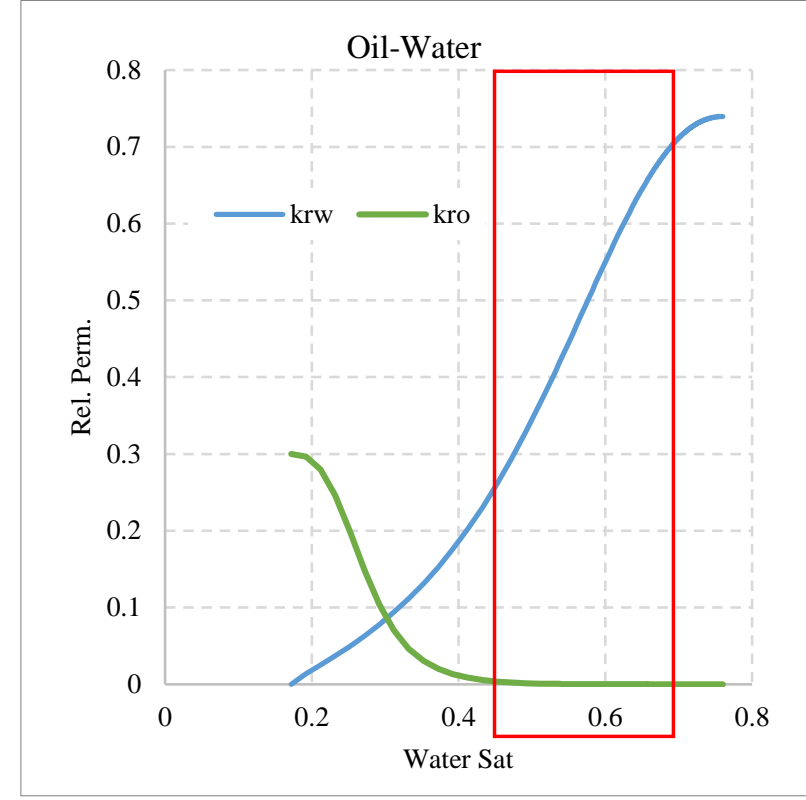

(a)

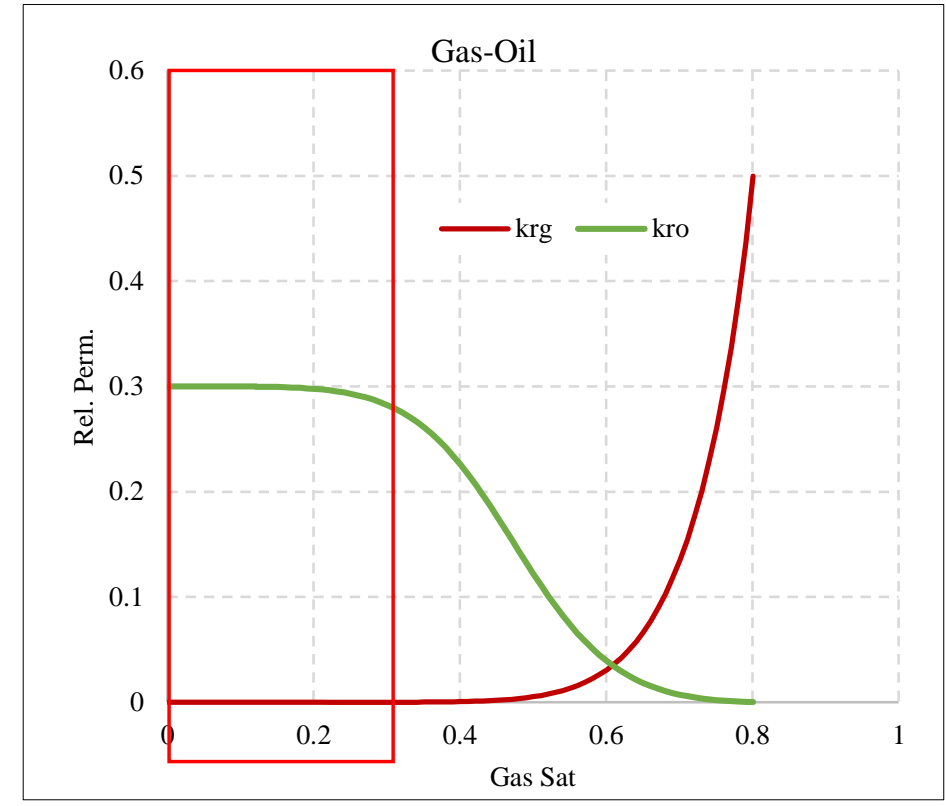

(b)

Figure 9: Relative permeability curves for oil/water (a) and gas/oil (b) tuned on the coreflood experiments estimated from co-history-matching. Red box highlights the gas and water saturation ranges controlling the results of simulations.

Table 5: Binary interaction coefficients of $\mathrm{CO}_{2}$ and hydrocarbon components tuned for different history matching approaches.

\begin{tabular}{|c|l|l|l|l|l|l|l|l|l|l|}
\hline Components & C1 & C2toC3 & C4toC7 & C8toC9 & C10toC15 & C16toC20 & C21toC25 & C26toC31 & C32to C33 & C34+ \\
\hline Co-history-matched & -0.04 & -0.03 & 0.61 & 0.19 & -0.89 & 0.58 & 0.68 & -0.41 & -0.54 \\
\hline Single coreflood & 1.73 & -0.92 & 1.18 & -0.04 & -0.58 & 0.08 & 0.51 & -0.5 & 0.2 \\
\hline
\end{tabular}

Having matched the coreflood experiment together, a series of in-situ changes can be numerically estimated. Figure 10 shows the average gas saturation formed in the core during 
the secondary and tertiary carbonated water injection experiments. As was directly observed in micromodel experiments (Mahzari, et al., 2018), the average gas saturation in secondary mode would be notably higher than that of tertiary test, which was reproduced in the simulation results. The final average gas saturation in the secondary and tertiary modes are 0.25 and 0.2 , respectively. Also, the rate of gas phase forming in the core is faster in the secondary mode compared to tertiary one. In terms of dynamic compositional behaviour between resident oil and evolving gas, Figure 11-a depicts the profile of interfacial tension (IFT) between oil and gas in the $10^{\text {th }}$ grid during secondary carbonated water injection. As observed experimentally in Figure 3, IFT of oil and gas would have a decreasing trend toward a very low value (in some cases IFT vanished). Similarly, the simulation results have indicated a decreasing trend in IFT to a very low value of $0.03 \mathrm{dyne} / \mathrm{cm}$. It should be pointed out that IFT of zero (gas and oil become one phase) between oil and gas could cause numerical convergence problems and hence could not be captured in the simulations. This decreasing trend in IFT can be linked to compositional variations (or enrichment) in the gas phase. Figure 11-b shows the compositional changes in the gas phase in the $10^{\text {th }}$ grid, which indicates liberation of methane in the beginning and then, $\mathrm{CO}_{2}$ is transferred into the gas phase reaching to concentration of $55 \%$. This behaviour is in agreement with experimental results of another study where multi-contact PVT experiments for carbonated water and live oil system were performed (Seyyedi, et al., 2017). As $\mathrm{CO}_{2}$ partitioned in the gas phase, intermediate rich components such as $\mathrm{C} 10-\mathrm{C} 15$ would be extracted into the gas phase, which can reduce the IFT notably.

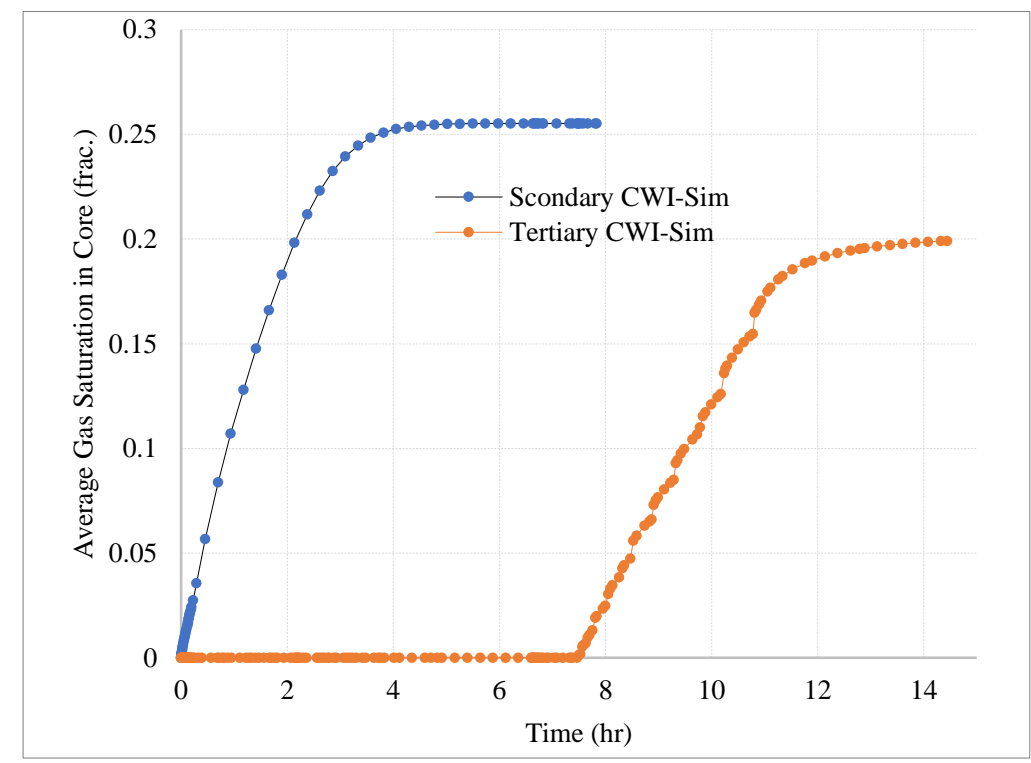

Figure 10: Simulation results of average gas saturation formed during tertiary and secondary carbonated water injection. Higher gas saturation was formed in the secondary carbonated water injection, which is in agreement with micromodel observations. 


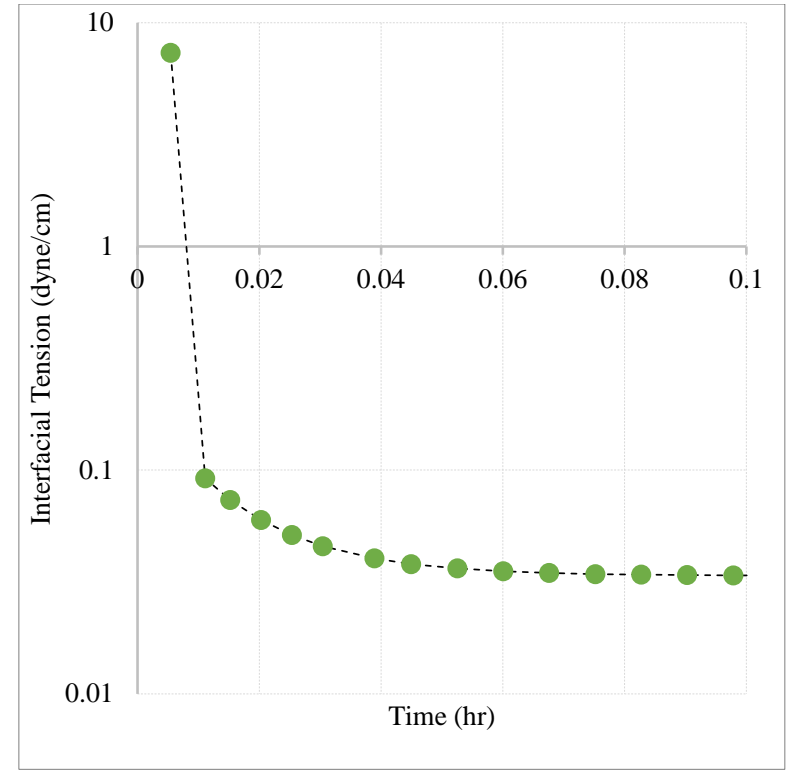

(a)

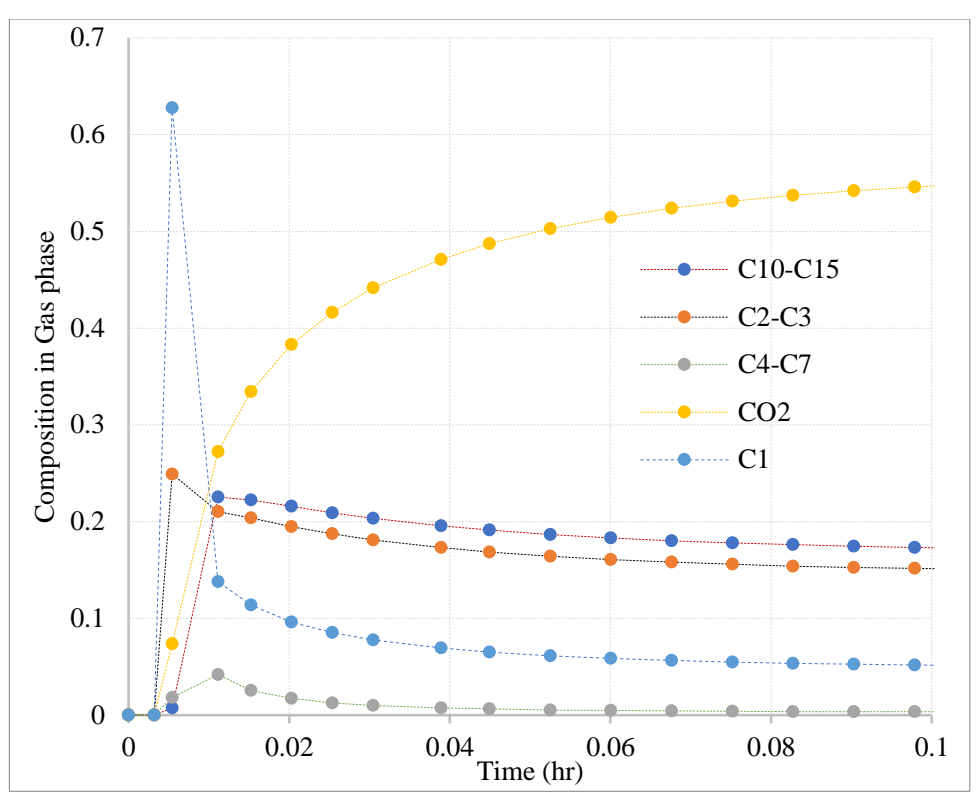

(b)

Figure 11: (a) Results of simulation for interfacial tension (IFT) between gas and oil in $10^{\text {th }}$ grid during secondary carbonated water injection. Decreasing trend of IFT was captured as reported from micromodel visualisations. (b) Results of simulation for compositional variations of gas phase in $10^{\text {th }}$ grid during secondary carbonated water injection. Intermediate oil components did enrich the gas phase as more $\mathrm{CO}_{2}$ is transferred to gas phase.

In summary, in the methodology developed for co-history-matching of similar coreflood experiments, the $\mathrm{CO}_{2}$ mass transfer and saturation functions were tuned to honour hard constraints ( $\mathrm{dP}$ and oil recovery profiles) and soft constraints (qualitative observations of micromodel tests). Although the matches were satisfactory, slight differences between experimental and simulation results were seen, which could be attributed to assumptions made in the simulation process. However, the approaches and the results would demonstrate an improved methodology and understanding for transfer of $\mathrm{CO}_{2}$ to resident live oil under reservoir conditions. On the other hand, one aspect of carbonated water injection in carbonate rocks is the geochemical interactions and in particular rock dissolution.

\section{Analysis of geochemical interactions}

Calcite-rich rocks like carbonates can be calcified as reactive porous media for $\mathrm{CO}_{2}$-rich water injection. Simulation of calcite dissolution and precipitation can be an essential aspect of carbonated water injection for enhanced oil recovery and $\mathrm{CO}_{2}$ storage purposes. In the sets of coreflood experiments considered in this work, the single phase experiment has indicated significant dissolution in the very inlet of the core. Also, it was reported that the average permeability of the core after extended period of carbonated water injection would not be changed notably (Mahzari, et al., 2017). These two findings can reflect that; in the absence of oil, precipitation of calcite may not be a significant process compared to dissolution. In this 
part, using CMG-GEM package with its geochemistry module, it has been attempted to match the calcite dissolution in the single phase experiment. The following reactions were included in the geochemical interactions between $\mathrm{CO}_{2}$-charged aqueous phase and calcite mineral;

$\mathrm{H}_{2} \mathrm{O} \rightleftarrows \mathrm{H}^{+}+\mathrm{OH}^{-}$

$\mathrm{H}_{2} \mathrm{O}+\mathrm{CO}_{2} \rightleftarrows \mathrm{H}^{+}+\mathrm{HCO}_{3}^{-}$

$\mathrm{H}^{+}+$Calcite $\rightleftarrows \mathrm{Ca}^{++}+\mathrm{HCO}_{3}^{-}$

Firstly, the reaction parameters of $\mathrm{CO}_{2}$-charged aqueous phase and calcite mineral was tuned to match the single phase core experiment (no oil was present). The matched model is then utilised to simulate the rock dissolution in the presence of oil. It should be noted that, from the data set used in this work, no geochemical data is available for calcite dissolution in the presence of oil. The only information from rock dissolution/precipitation is the general observation that the core permeability did not change notably in the experiments performed in the presence of oil.

The rate of reaction for mineral dissolution and precipitation is controlled by equation 10 (Bethke, 1996):

$r_{i}=A_{i} k_{i}\left(1-\frac{Q_{i}}{K_{e q}}\right) \ldots \ldots$

Where $r, A$, and $k$ are rate, reactive surface area, and rate constant for mineral $i . K_{e q}$ is chemical equilibrium constant and $Q$ stands for activity of product in the reaction. Depending on $\frac{Q_{i}}{K_{e q}}$, dissolution or precipitation take place. To match the single phase experiment, $A$ (reactive surface area) and $Q$ (activation energy) values were tuned to reproduce the experimental data. The test comprised two steps; plain water injection followed by carbonated water injection. Figure 12 shows the results of simulation compared against the experimental data. The surface area and activation energy were increased to $847 \mathrm{~m}^{2}$ per $\mathrm{m}^{3}$ of the bulk volume and 74136.25 $\mathrm{J} / \mathrm{mol}$, respectively. 


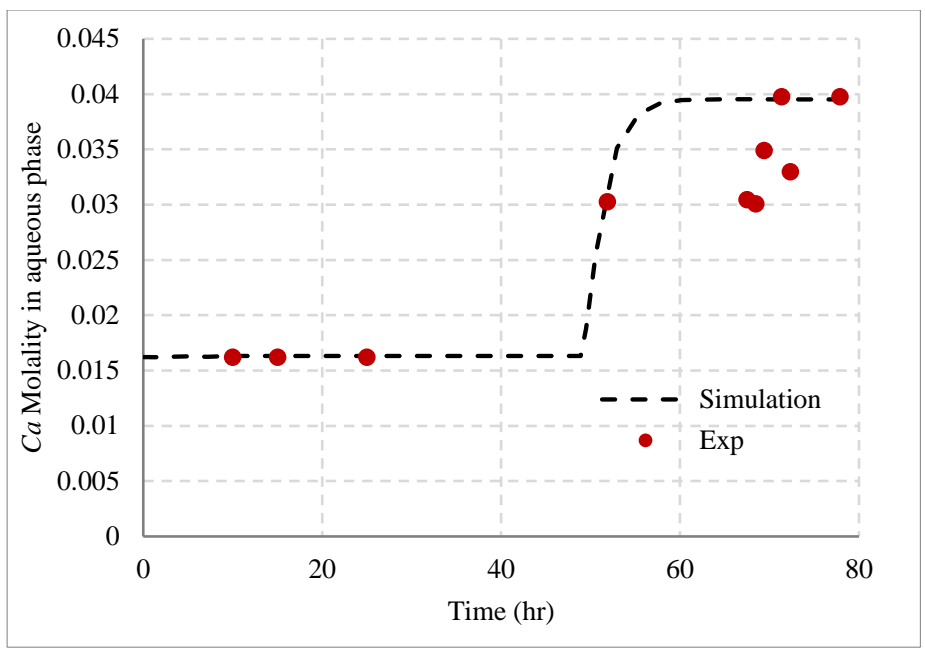

Figure 12: History-matching results of Ca molality in effluent during single phase injection of carbonated water. The test started with plain water injection followed by carbonated water injection.

In addition to the profile of effluent, another information can be used to compare the simulation results with experimental observation. After the single phase experiment, the core was weighed and, the change of weights of core plugs was reported. The total weight loss of the composite core due to dissolution measured after the experiment was $2.7 \mathrm{gr}$. However, the simulation results have indicated the total dissolution of $2.2 \mathrm{gr}$, which can be an acceptable similarity between simulation and experimental results. For detailed analysis of calcite dissolution, Figure 13 demonstrates the change in mineral content (dissolution) of grid cells along the core. Significant dissolution took place in the first two grids of the core close to inlet, which is in agreement with x-ray CT image of core (Figure 1-b). Also, it can be identified that the extent of dissolution is similar in the grids after $5^{\text {th }}$ grid away from the inlet.

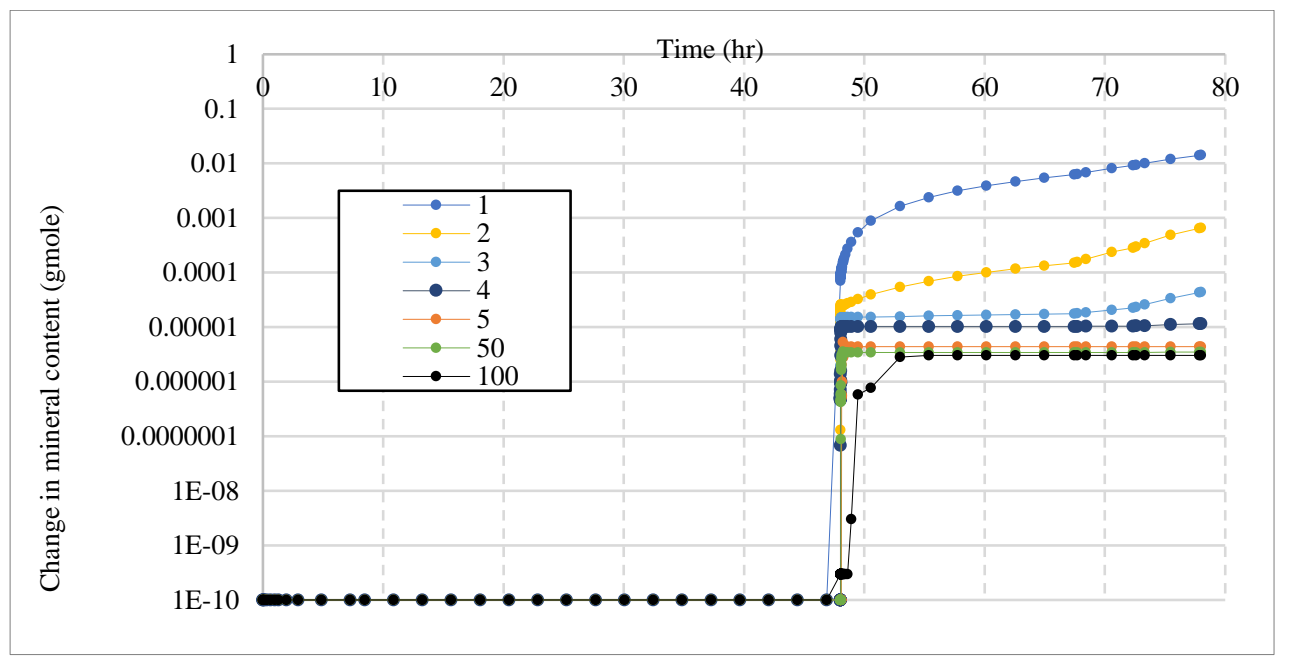

Figure 13: In semi logarithm plot, simulation results for calcite dissolution (expressed in change in minerals) in different grids during single phase carbonated water injection. Significant dissolutions took place in the first grid (inlet), which is in agreement with $\mathrm{x}$-ray CT image of core taken after the experiment (Figure 1-b) 
The single phase experiment was matched using geochemical parameters of calcite reaction with carbonated water. Also, having performed co-history-matching of similar coreflood experiment for enhanced oil recovery, the $\mathrm{CO}_{2}$ transfer from aqueous phase into the live oil and consequent gas phase formation was captured. Although experimental data for geochemistry in the presence of oil is not available, numerical simulation can be performed to evaluate the extent of dissolution and precipitation in the presence of oil. It is believed that $\mathrm{CO}_{2}$ would have a strong tendency to be partitioned into live oil, which would in turn affect the geochemistry as carbonation level of the flowing aqueous phase would be reduced. Also, in the presence of oil, the surface of calcite rock can be coated with the oil diminishing the contact area between carbonated water and calcite mineral, which is similarly reported for brine-rock interaction in the presence of oil (Farajzadeh, et al., 2017). From oil/water relative permeability and capillary pressure curves, it can be inferred that the core would have an oil wet state, which would impact the rock/brine interactions notably. Figure 14 illustrates the profiles of $\mathrm{Ca}^{++}$ molality with and without the presence of oil, which resulted from coupling calcite reaction with enhanced oil recovery for tertiary carbonated water. Dissolution of calcite would occur in both cases, i.e. with and without presence of oil. However, as can be seen in Figure 14, in the presence of oil, the concentration of $\mathrm{Ca}^{++}$is considerably reduced, which implies significantly less dissolution of calcite in the presence of oil.

Dissolution and precipitation of calcite would affect porosity and permeability of the core. Figure 15 demonstrates porosity and permeability ratio $\left(\frac{\mathrm{k}}{\mathrm{k} 0}\right)$ of the cores at the end tertiary carbonated water injection (with and without presence of oil). In the naked core, which is fully exposed to the flowing carbonated water, the porosity in the inlet of the core would be increased to 0.45 (from original value of 0.23 ) whereas, in the presence of oil, it would be raised to 0.271 (from original value of 0.258 ). For the permeability ratio, which is calculated from the changes in porosity using Karman-Cozney correlation with exponent of 3. To extend our simulation results to the entire core length (Figure 15 focused on first two centimetre of the core), Figure 16 illustrates the porosity of the core at the end of tertiary carbonated water injection in the presence of oil. In the vicinity of the core outlet, insignificant degree of precipitation can be seen in simulation results, which can be attributed to loss of $\mathrm{CO}_{2}$ to the resident oil and carbonated water being depleted from its acidity. These results are in agreement with general observations reported in the experimental information where the core permeability did not change notably after the experiments (Mahzari, et al., 2017). Therefore, since the average porosity and permeability of the cores remained similar in the experiments, the results of 
simulations can be interpreted as insignificant dissolution and precipitation of calcite during carbonated water injection. Even in the high extent of dissolution in the naked core, the core integrity was not undermined due to rock weakening. However, in large scales, large volumes of carbonated water would flow near the injection wellbore, which may adversely affect well integrity.

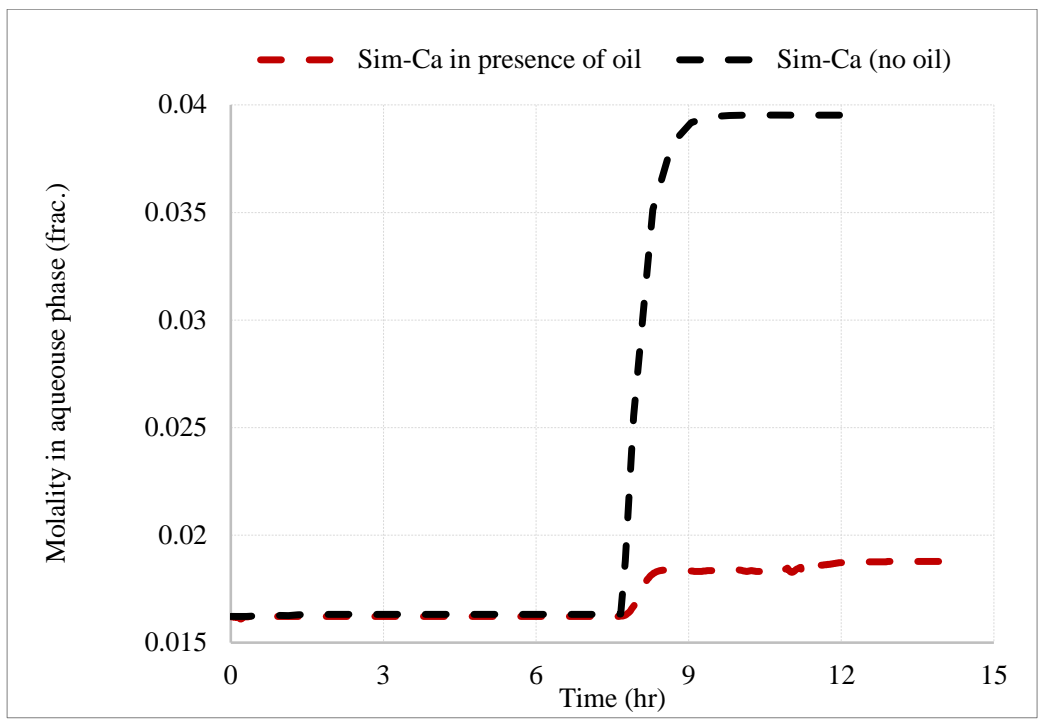

Figure 14: Results of simulation of $\mathrm{Ca}^{++}$molality in aqueous effluent with and without the presence of oil. Presence of oil would impact calcite dissolution significantly.

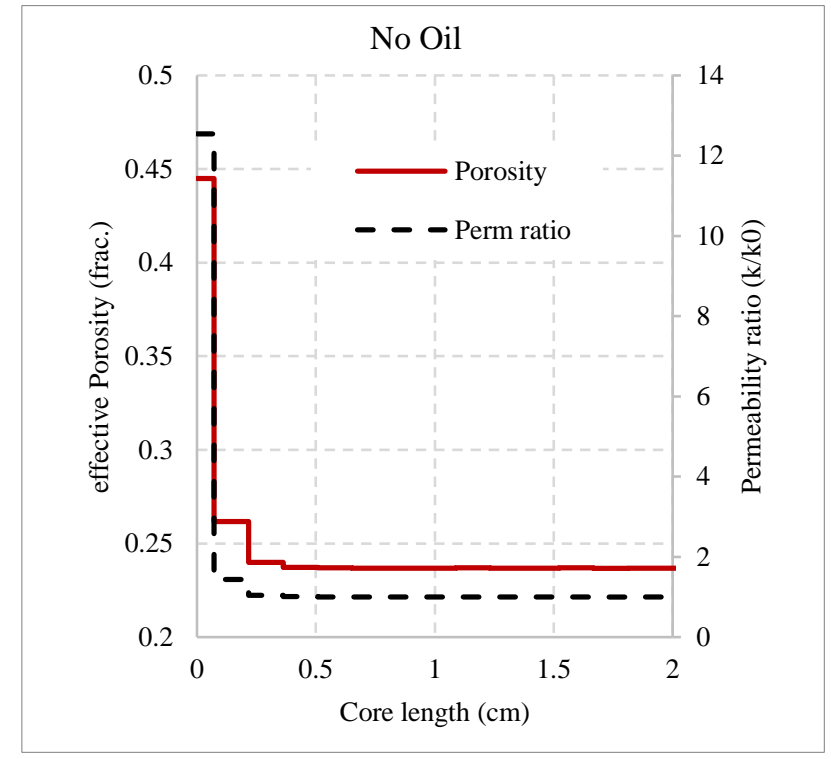

(a)

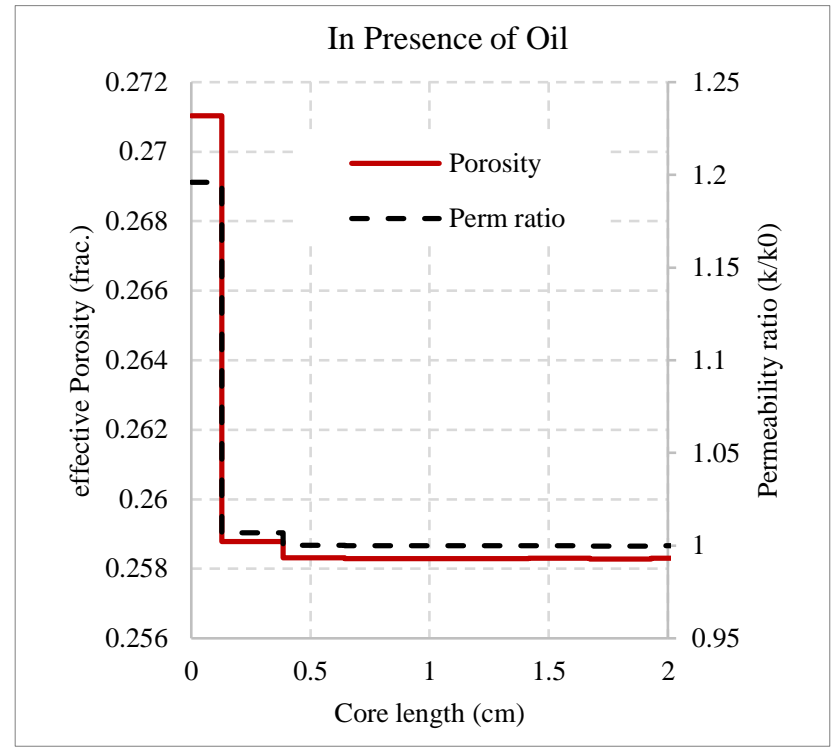

(b)

Figure 15: For first $2 \mathrm{~cm}$ of the core, effective porosity and permeability ratio $\left(\frac{k}{k 0}\right)$ during carbonated water injection with and without the presence of oil (simulation results). Calcite dissolution occurs in the very inlet. Presence of oil can reduce the calcite dissolution significantly. 


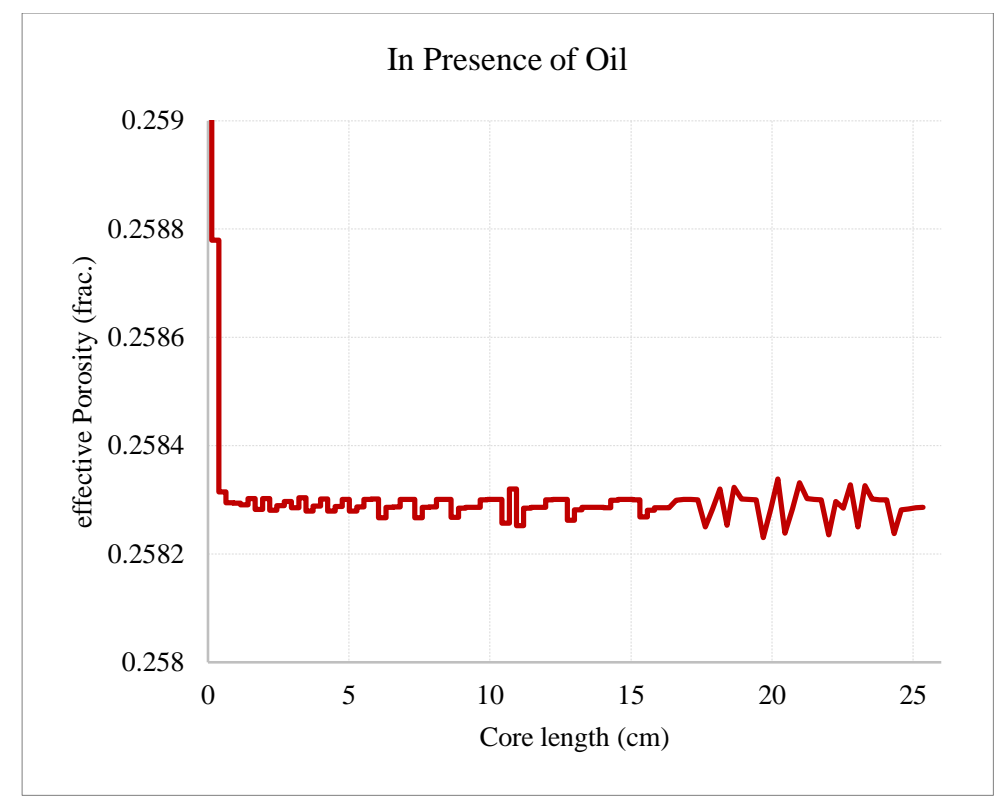

Figure 16: For full core length, effective porosity of the core at end of carbonated water injection indicating dissolution and precipitation of calcite took place intermittently.

\section{Large scale implications}

In the core scale simulation results, it was identified that significant additional oil recovery can be achieved while marginal rock dissolution would occur in presence of oil. In the original paper for the laboratory experiment, it was stated that the core used for corefloods did not experience remarkable dissolution and failure of integrity. Also, the simulation results demonstrated in Figure 15 can indicate that, presence of oil would reduce the dissolution rate significantly, if compared to No Oil case. Therefore, it can be inferred that the experiments and analyses of the dissolution should be investigated in the presence of oil (as oil would have high capacity to absorb $\mathrm{CO}_{2}$ and hence, reduction in dissolution). However, in the larger scales, the carbonate rock in the vicinity of the wellbore would be flushed by massive volume of $\mathrm{CO}_{2}$ enriched water. To sensitise the impact of rock dissolution and enhanced oil recovery in larger scales; three simulation runs were performed in a radial sector to demonstrate the differences in laboratory and large scales; (i) plain water flood for 10 years, (ii) two years of plain water flood followed by 8 years of carbonated water injection, and (iii) two years of plain water flood followed by four years of carbonated water and final water flood for four years. The rationale for selecting these scenarios are related to degree of rock dissolution around the injection wellbore. Continuous injection of carbonated water for 8 years would cause uncontrollable calcite dissolution and hence, it was modified to plain waterflood after four years. Figure 17 illustrates schematically the sector model with one injection well and 5 producing wells perforated for full sector thickness. Table 6 lists properties of the sector model. The fluid placed 
in the model was identical to the core-scale simulation. Also, same relative permeability model (Figure 9) was input. The objective of this sector simulation is to show the difference between core-scale laboratory analysis and field scale implications.

Table 6: Description of radial sector model for large scale simulations

\begin{tabular}{|l|l|}
\hline Number of grids $(\mathrm{x}, \mathrm{y}, \mathrm{z})$ & $13 \times 10 \times 10$ \\
\hline$\Delta \mathrm{x}(\mathrm{ft})$ & $5,5 \times 10,5 \times 20,40,80$ \\
\hline$\Delta \mathrm{y}($ degree $)$ & 36 \\
\hline$\Delta \mathrm{z}(\mathrm{ft})$ & 10 \\
\hline Porosity & 0.258 \\
\hline Permeability $(\mathrm{mD})$ & 96.21 \\
\hline Injection rate $(\mathrm{bbl} /$ day) & 1000 \\
\hline Production bottom hole pressure $(\mathrm{psi})$ & 3100 \\
\hline
\end{tabular}

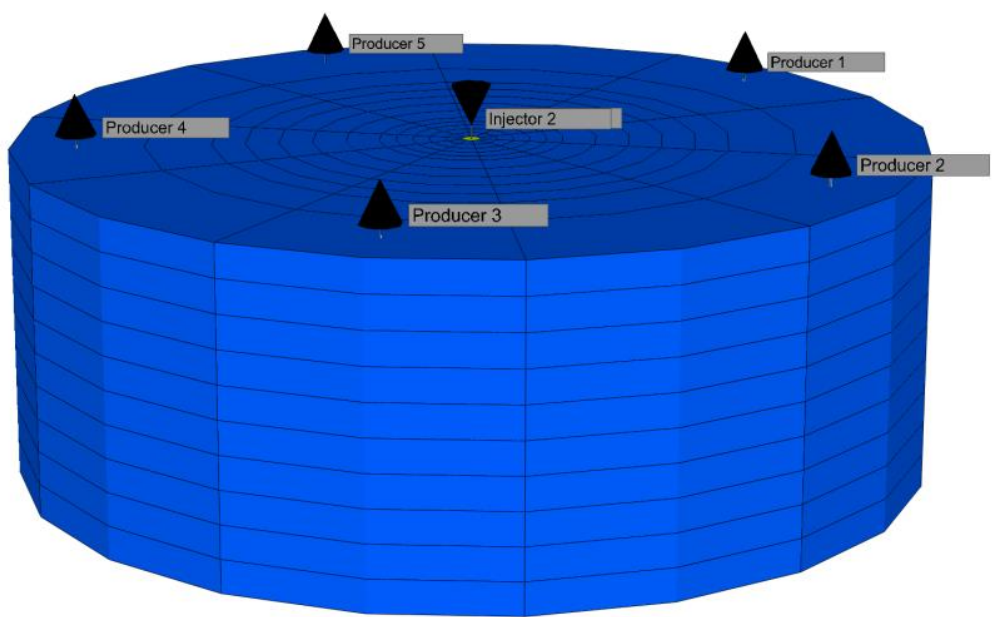

Figure 17: Radial sector model constructed for large-scale simulation of carbonated water injection. Injection well was perforated in the centre.

Firstly, the tertiary carbonated water injection was performed in a continuous mode and the results indicated remarkable dissolutions around the injection wellbore. Figure 18 illustrates the map of porosity in the sector mode which demonstrates an increase of porosity for the grid adjacent to injection well to 0.85 , which can be translated to complete wearing out of the wellbore. Therefore, continuous injection of carbonated water would lead wellbore failure. However, to alleviate this issue, it can be suggested to perform carbonated water injection for a short cycle. Figure 19 shows the profiles of porosity of the grid cell adjacent to the injection wellbore for three simulation cases. Continuous injection of carbonated water would wear out the carbonate rock around the wellbore with extreme degree of dissolution. The porosity of the grid cell $(1,1,1)$ would reach to 0.65 from the original value of 0.258 , which can jeopardise the well integrity due to rock weakening (Carey, et al., 2010). However, performing the third 
scenario (i.e. short cycle of carbonated water), the rock porosity would remain under 0.45 if the carbonated water injection is followed by plain water injection. The criterion of 0.45 for porosity is selected from the single phase coreflood experiment where porosity reach to 0.45 but core integrity did not undermine under fixed stress of overburden.

On the other hand, Figure 20 demonstrates the profiles of oil recovery for three simulation cases. For this ten years of injection strategies, $6.2 \%$ of additional oil recovery can be attained by tertiary carbonated water injection. Interestingly, when the short cycle of four years of carbonated water injection was performed, similar additional oil recovery was achieved. In other words, in order to manage the rock dissolution around the wellbore, short cycle of carbonated water injection can be injected, which would lead to similar additional oil recovery if compared to continuous carbonated water injection. The similar oil recovery achieved by these two cases ( 8 years of continuous carbonated water versus 4 years of carbonated water followed by plain water) can be attributed to two factors: in the case with shorter cycles of carbonated water injection (i) the chasing plain water would firstly displace the resident carbonated water, which would have the same impact and hence, similar oil recovery and also (ii) the dominant mechanism for oil recovery by carbonated water is creation of gas phase and three-phase flow, therefore, the chasing plain water would lead to additional oil recovery due to in-situ WAG type of flow as explain by Mahzari et al. (Mahzari, et al., 2018). As can be observed in Figure 20, the oil recovery curve of short cycle carbonated water injection has started to deviate from continuous carbonated water injection, which can be attributed to stripping effects of the chasing plain water, which extracted the $\mathrm{CO}_{2}$ pre-dissolved in the gas and oil. 


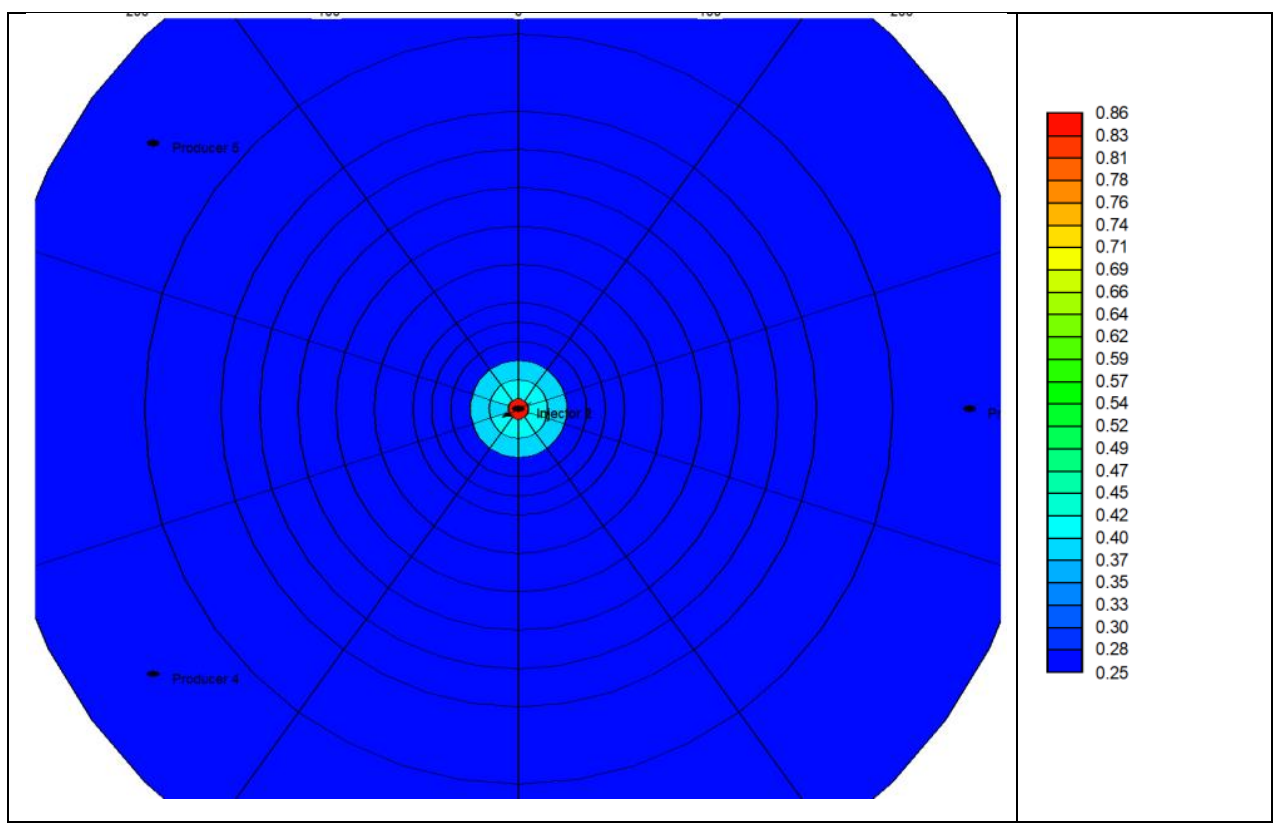

Figure 18: Map of porosity in the radial model demonstrating extreme dissolution around the wellbore.

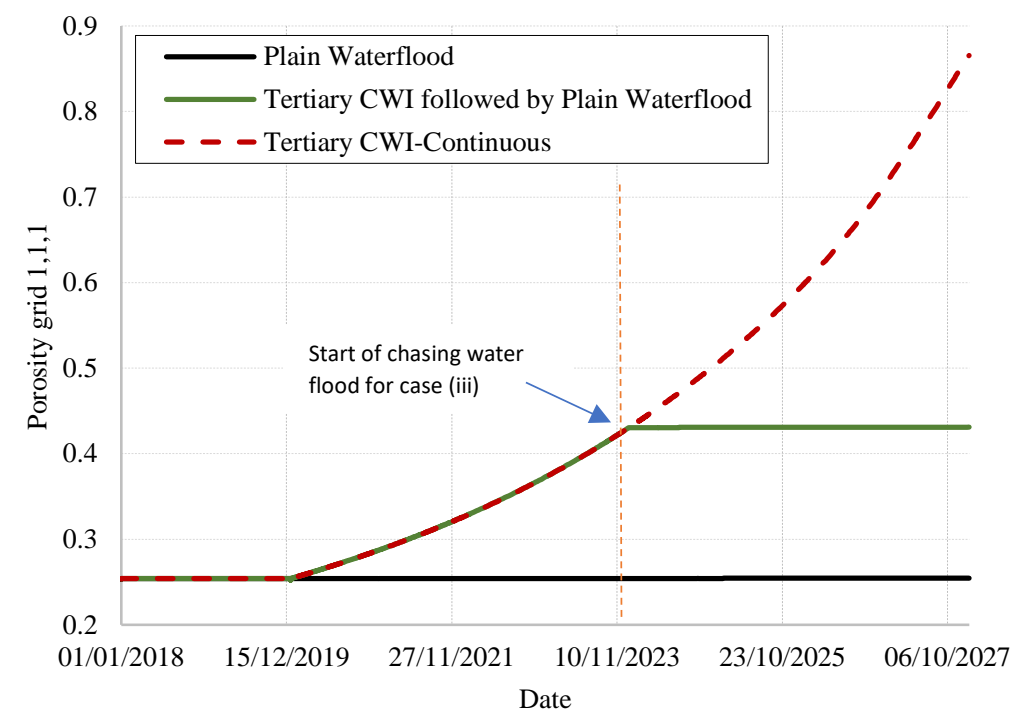

Figure 19: Porosity of a gird $(1,1,1)$ adjacent to the injection wellbore with respect to time for three simulation cases.

Continuous injection of carbonated water would lead to extreme rock dissolution around wellbore. Injection of short cycle of carbonated water followed by waterflood can maintain rock integrity while it can result in same additional oil recovery. The injection of the plain water in the green curve was commenced on 01/01/2024. The dissolution in the small radial grid $(1,1,1)$ was stopped shortly after the injection of plain water commenced. 


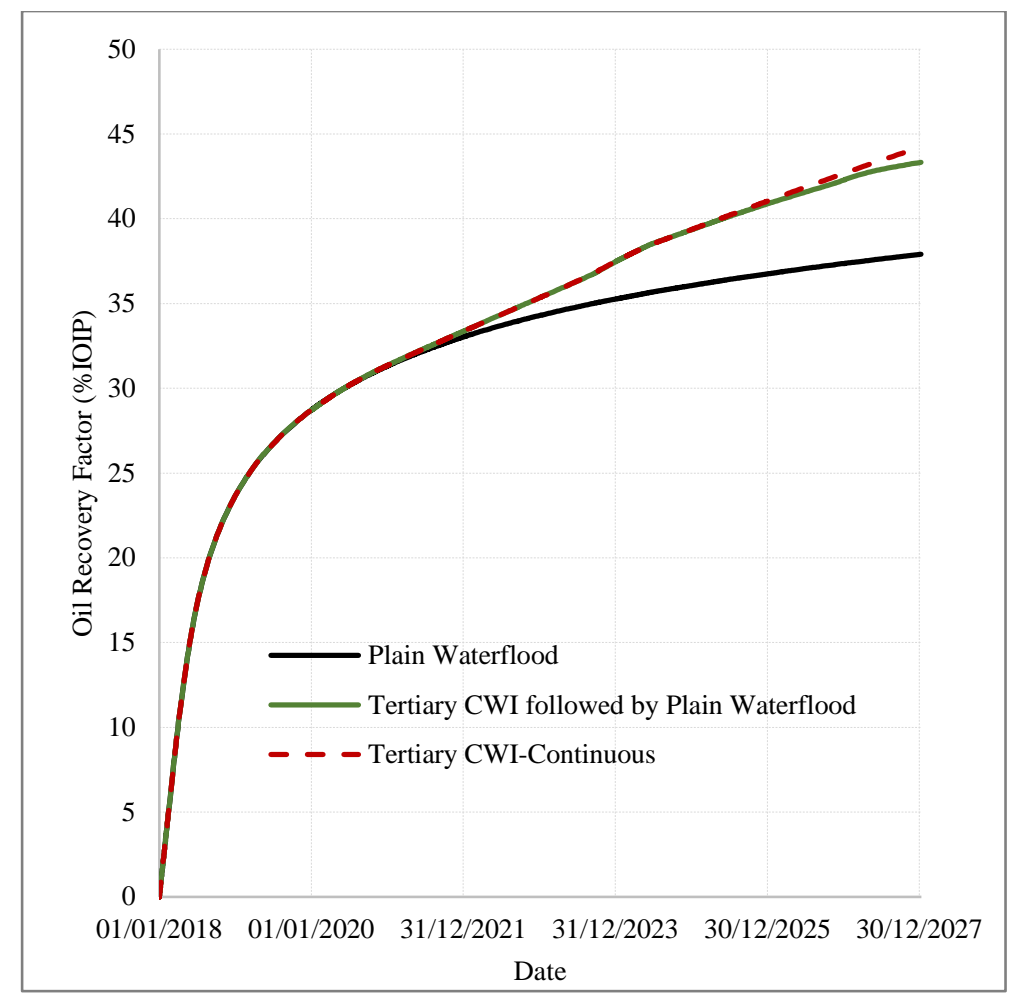

Figure 20: Profiles of oil recovery for three simulation cases. Tertiary carbonated water injection would lead to $6.2 \%$ additional oil recovery compared to plain water injection. Similar additional oil recovery can be achieved with short cycle of carbonated water injection, which would alleviate the concerns over rock dissolution around injection wellbore.

\section{Discussion}

Using the experimental data for enhanced oil recovery and geochemical interactions during carbonated water injection in carbonate rock, the simulation results have demonstrated that rock dissolution would not be significant in laboratory scales. However, the sector model has indicated that calcite dissolution around the injection wellbore can result in substantial increase in grid cell porosity, which can be translated into extreme rock dissolution. This difference of laboratory and sector models is the linear flow (core model) versus radial flow (sector model). In the radial flow, the cross section and grid volume around wellbore is relatively small, which can higher dissolution in the grid adjacent to the wellbore. Therefore, as opposed to laboratory findings, $\mathrm{CO}_{2}$ transfer from carbonated water to the resident oil would not alleviate the concerns over rock dissolution. However, injection of short cycle of carbonated water can alleviate the problem of wellbore integrity while achieving similar quantities of enhanced oil recovery. Therefore, it can be suggested to perform laboratory experiments with different cycles of carbonated water chased with plain water to be able to further tune the model. The results of this study would highlight the fact that more detailed analyses of geo-mechanical, fluid flow, geochemical, and mass transfer for carbonated water injection (and also, $\mathrm{CO}_{2}-\mathrm{WAG}$ scenarios) in carbonate reservoirs are essential. In other words, carbonated water injection and 
$\mathrm{CO}_{2}$-WAG in carbonate reservoir can be efficiently implemented if the injection scenario is optimised with an integrated approach to account for three-phase flow and dissolution/precipitation in the presence of live oil.

\section{Conclusions}

Through the integrated simulation study of enhanced oil recovery and geochemical interactions, the injection of $\mathrm{CO}_{2}$-enriched water in carbonate rock was investigated in tertiary and secondary modes. The results of a series of coreflood experiments were history-matched. The new approach employed in this work (i.e. co-history-matching) could enable capturing quantitative (oil recovery and $\mathrm{dP}$ profiles) and qualitative observations (direct visualisations). To match secondary and tertiary coreflood experiments simultaneously, binary interaction coefficients between $\mathrm{CO}_{2}$ and oil components and gas-oil relative permeability curves were tuned. Formation of gas phase during carbonated water was captured in the co-historymatching. Also, the gas/oil relative permeability curves were adjusted in the way that high critical gas saturation and steady oil relative permeability were obtained. IFT between oil and gas did exhibit the decreasing trend indicating extraction of intermediate hydrocarbon components into the in-situ gas phase.

History matching of rock dissolution during single phase carbonated water injection could be obtained by adjusting rock surface area and activation energy of calcite reaction. The simulation results of laboratory scales also demonstrate that, rock dissolution would be insignificant in the presence of oil due to $\mathrm{CO}_{2}$ transfer to the oil and depletion of flowing aqueous phase from its acidity. However, a series of simulations in the radial sector model were performed, which highlighted the fact that significant rock dissolution would take place in the vicinity of the injection wellbore. To alleviate this problem, carbonated water injection for short cycle can be performed while similar quantity of enhanced oil recovery could be attained. In the sector mode, $6.2 \%$ of additional oil recovery could be obtained by carbonated water injection. Overall, this study would manifest the importance of integrated simulation of geochemical, geo-mechanical, fluid flow, and mass transfer during injection of $\mathrm{CO}_{2}$-enriched water such as carbonated water and $\mathrm{CO}_{2}-\mathrm{WAG}$ scenarios.

\section{Acknowledgements}

This work is part of the Science for Clean Energy research consortium funded by European Union's Horizon 2020 research and innovation programme. 


\section{References}

Al Mesmari, A., Mahzari, P. \& Sohrabi, M., 2016. An Improved Methodology for Simulating Oil Recovery by Carbonated Water Injection: Impact of Compositional Changes. Dubai, UAE, SPE Annual Technical Conference and Exhibition.

Al Mesmari, A., Mahzari, P. \& Sohrabi, M., 2016. Modelling Formation of a New Fluid Phase During Carbonated Water Injection. Bangkok, Thailand, International Petroleum Technology Conference.

Alizadeh, A. H., Khishvand, M., Ioannidis, M. A. \& Piri, M., 2014. Multi-scale experimental study of carbonated water injection: An effective process for mobilization and recovery of trapped oil. Fuel, Volume 132, pp. 219-235.

Baker, L. E., 1988. Three-Phase Relative Permeability Correlations. Tulsa, Oklahoma, SPE Enhanced Oil Recovery Symposium.

Bethke, C. M., 1996. Geochemical Reaction Modeling. New York, Oxford: Oxford University Press.

Blackford, T. A., 1987. Carbonated waterflood implementation and its impact on material performance in a pilot project. Dallas, Texas, SPE annual technical conference and exhibition.

Carey, J. W. et al., 2010. Experimental investigation of wellbore integrity and CO2-brine flow along the casing-cement microannulus. International Journal of Greenhouse Gas Control, 4(2), pp. 272-282.

Christensen, R. J., 1961. Carbonated Waterflood Results-Texas And Oklahoma. Farmington, New Mexico, Annual meeting of rocky mountain petroleum engineers of AIME.

Coutinho, J. A., Kontogeorgis, G. M. \& Stenby, E. H., 1994. Binary Interaction parameters for nonpolar systems with cubic equation of state: a theoritical approach 1.

CO2/hydrocarbons using SRK equation of state. Fluid Phase Equilibria, Volume 102, pp. 3160.

Coutinho, J. A., Vlamos, P. M. \& Kontogeorgis, G. M., 2000. General Form of the CrossEnergy Parameter of Equations of State. Ind Eng Chem Res, Volume 39, pp. 3076-3082.

de Nevers, N., 1964. A calculation method for carbonated water flooding. SPE Journal, Volume 4, pp. 9-20.

Douchenne, S., de Loubens, R., Petitfrere, M. \& Joubert, M., 2015. Modeling and simultaneous history-matching of multiple WAG experiments at reservoir conditions. Abu Dhabi, UAE, Adu Dhabi International Petroleum Exhibition and Conference.

Farajzadeh, R., Guo, H., van Winden, J. \& Bruining, J., 2017. Cation Exchange in the Presence of Oil in Porous Media. ACS Earth Space Chemistry, 1(2), pp. 101-112.

Fateen, S. K., Khalil, M. M. \& Elnabawy, A. O., 2013. Semi-empirical correlation for binary interaction parameters of the Peng-Robinson equation of state with the van der Waals mixing rules for the prediction of high-pressure vapor-liquid equilibrium. Journal of Advanced Research, 4(2), pp. 137-145. 
Foroozesh, J., Jamiolahmady, M. \& Sohrabi, M., 2016. Mathematical modeling of carbonated water injection for EOR and $\mathrm{CO} 2$ storage with a focus on mass transfer kinetics. Fuel, Volume 174, pp. 325-332.

Honarpour, M. \& Mahmoud, S. M., 1988. Relative-Permeability Measurements: An Overview. Journal of Petroleum Technology, 40(08), pp. 963-966.

Ikeda, M. K. \& Schaefer, L. A., 2011. Examining the effect of binary interaction parameters on VLE modelling using cubic equations of state. Fluid Phase Equilibria, 25(2), pp. 233-237.

Kechut, N. I., Jamiolahmady, M. \& Sohrabi, M., 2011. Numerical simulation of experimental carbonated water injection (CWI) for improved oil recovery and CO2 storage. Journal of Petroleum Ecience and Engineering, 77(1), pp. 111-120.

Lomeland, F., Ebeltoft, E. \& Thomas, W. H., 2005. A new versatile relative permeability correlation. Toronto, Canada, Society of Core Analysts.

Mahzari, P., Al Mesmari, A. \& Sohrabi, M., 2018. Co-history Matching: A Way Forward for Estimating Representative Saturation Functions. Transport in Porous Media, 125(3), pp. 483501.

Mahzari, P. \& Sohrabi, M., 2017. A robust methodology to simulate water-alternating-gas experiments at different scenarios under near-miscible conditions. SPE Journal, Volume 22, pp. 1506-1518.

Mahzari, P. \& Sohrabi, M., 2017. An improved approach for estimation of flow and hysteresis parameters applicable to WAG experiments. Fuel, Volume 197, pp. 359-372.

Mahzari, P. et al., 2017. A Comprehensive Experimental Study of Pore-Scale and Core-Scale Processes During Carbonated Water Injection Under Reservoir Conditions. Dammam, Saudi Arabia, SPE Kingdom of Saudi Arabia Annual Technical Symposium and Exhibition.

Mahzari, P. et al., 2018. Carbonated water injection under reservoir conditions; in-situ WAGtype EOR. Fuel, Volume 217, pp. 285-296.

Manrique, E. J., Muci, V. E. \& Gurfinkel, M. E., 2007. EOR Field Experiences in Carbonate Reservoirs in the United States. SPE Reservoir Evaluation \& Engineering, 10(06), pp. 667686.

Meyssami, B., Balaban, M. O. \& Teixeira, A., 1992. Prediction of $\mathrm{pH}$ in model systems pressurized with carbon dioxide. Biotechnol Prog, Volume 8, pp. 149-154.

Mosavat, N. \& Torabi, F., 2014. Application of CO2-saturated water flooding as a prospective safe CO2 storage strategy. Energy Procedia, Volume 63, pp. 5619-5630.

Oelkers, E. H., Gislason, S. R. \& Matter, J., 2008. Mineral Carbonation of CO2. Element, 4(5), pp. 333-337.

Ott, H. \& Oedai, S., 2015. Wormhole formation and compact dissolution in single- and twophase CO2-brine injections. Geophysical Research Letters, 42(7), pp. 2270-2276.

Peng, D. \& Robinson, D., 1976. A new Two-Constant Equation of State. Ind Eng Chem Fundam, Volume 15, pp. 50-64. 
Riazi, M., Sohrabi, M. \& Jamiolahmady, M., 2011. Experimental study of pore-scale mechanisms of carbonated water injection. Transport in Porous Media, Volume 86, pp. 7386.

Seyyedi, M., Mahzari, P. \& Sohrabi, M., 2017. An integrated study of the dominant mechanism leading to improved oil recovery by carbonated water injection. J Indust Eng Chem, Volume 45, pp. 22-32.

Seyyedi, M. \& Sohrabi, M., 2017. Pore-scale investigation of crude oil/CO2 compositional effects on oil recovery by carbonated water injection. Ind Eng Chem Res, Volume 56, pp. 1671-1681.

Snippe, J., Berg, S., Ganga, K. \& Brussee, N., 2018. Experimental and numerical investigation of wormholing during CO2 storage and Water Alternating Gas injection. SaintMalo, France, Computational Methods in Water Resources XXII.

Snippe, J., Gdanski, R. \& Ott, H., 2017. Multiphase modelling of wormhole formation in carbonates by the injection of CO2. Energy Procedia, Volume 114, pp. 2972-2984.

Sohrabi, M. et al., 2011. Carbonated water injection (CWI)-A productive way of using CO2 for oil recovery and CO2 storage. Energy Procedia, Volume 4, pp. 2192-2199.

Svec, R. K. \& Grigg, R. B., 2001. Physical Effects of WAG Fluids on Carbonate Core Plugs. New Orleans, Louisiana, SPE Annual Technical Conference and Exhibition. 